\title{
NHC-Based Iron Sensitizers for DSSCs
}

\author{
Thibaut Duchanois ${ }^{1}, \mathrm{Li} \mathrm{Liu}^{2}$, Mariachiara Pastore ${ }^{3}$, Antonio Monari ${ }^{3}{ }^{(\mathbb{D}}$, Cristina Cebrián ${ }^{4}$ (D), \\ Yann Trolez ${ }^{5}$, Mohamed Darari ${ }^{1}$, Kevin Magra ${ }^{4}$, Antonio Francés-Monerris ${ }^{3}$ (D), \\ Edoardo Domenichini ${ }^{2}$, Marc Beley ${ }^{1}$, Xavier Assfeld ${ }^{3}$, Stefan Haacke ${ }^{2}$ \\ and Philippe C. Gros 1 * (D) \\ 1 Université de Lorraine, CNRS, L2CM, F-54000 Nancy, France; thibaut.duchanois@lafouillotte.fr (T.D.); \\ mohamed.darari@univ-lorraine.fr (M.D.); marc.beley@univ-lorraine.fr (M.B.) \\ 2 Université de Strasbourg, CNRS, IPCMS, F-67000 Strasbourg, France; li.liu@ipcms.unistra.fr (L.L.); \\ edoardo.domenichini@ipcms.unistra.fr (E.D.); stefan.haacke@ipcms.unistra.fr (S.H.) \\ 3 Université de Lorraine, CNRS, LPCT, F-54000 Nancy, France; mariachiara.pastore@gmail.com (M.P.); \\ antonio.monari@univ-lorraine.fr (A.M.); antonio.frances@univ-lorraine.fr (A.F.-M.); \\ xavier.assfeld@univ-lorraine.fr (X.A.) \\ 4 Université de Lorraine, CNRS, L2CM, F-57000 Metz, France; cristina.cebrian-avila@univ-lorraine.fr (C.C.); \\ kevin.magra@univ-lorraine.fr (K.M.) \\ 5 Université Rennes, Ecole Nationale Supérieure de Chimie de Rennes, CNRS, ISCR, F-35000 Rennes, France; \\ yann.trolez@ensc-rennes.fr \\ * Correspondence: philippe.gros@univ-lorraine.fr; Tel.: +33-372-745-684
}

Received: 25 May 2018; Accepted: 15 June 2018; Published: 19 June 2018

\begin{abstract}
Nanostructured dye-sensitized solar cells (DSSCs) are promising photovoltaic devices because of their low cost and transparency. Ruthenium polypyridine complexes have long been considered as lead sensitizers for DSSCs, allowing them to reach up to $11 \%$ conversion efficiency. However, ruthenium suffers from serious drawbacks potentially limiting its widespread applicability, mainly related to its potential toxicity and scarcity. This has motivated continuous research efforts to develop valuable alternatives from cheap earth-abundant metals, and among them, iron is particularly attractive. Making iron complexes applicable in DSSCs is highly challenging due to an ultrafast deactivation of the metal-ligand charge-transfer (MLCT) states into metal-centered (MC) states, leading to inefficient injection into $\mathrm{TiO}_{2}$. In this review, we present our latest developments in the field using $\mathrm{Fe}(\mathrm{II})$-based photosensitizers bearing $\mathrm{N}$-heterocyclic carbene (NHC) ligands, and their use in DSSCs. Special attention is paid to synthesis, photophysical, electrochemical, and computational characterization.
\end{abstract}

Keywords: iron complexes; NHC ligands; excited states; photophysics

\section{Introduction}

Replacement of fossil fuels is one of the major concerns mankind is currently facing. To keep fulfilling an always-increasing energy demand, along with a reduction of greenhouse gas emissions, renewable energies are undoubtedly the most appealing alternative for a long-term sustainable solution for our society. Therefore, huge investments have been made during the last decades to develop commercially viable technologies to convert these renewable energies. Among these, the sun is a clean, secure energy source that can supply in just one day the whole world's energy demand of an entire year in just one day. In consequence, photovoltaic (PV) devices based on light harvesting and its conversion into electricity have been actively investigated. As an alternative to typical solar cells based on expensive, highly pure semiconductor materials, nanostructured dye-sensitized solar cells (DSSCs) are promising photovoltaic devices because of their low-cost fabrication process and 
partial transparency [1-3]. Their principle is to collect photons using a dye, also called a sensitizer, linked to a photoanode (coated with nanocrystalline $\mathrm{TiO}_{2}$ semiconductor (SC)). The light-induced dye excitation is followed by a fast electron injection into the SC. A redox electrolyte subsequently regenerates the dye's ground state. The oxidized form of the mediator is finally regenerated by reduction at the cathode, thus forming a current source for electrical circuits. Ruthenium polypyridine complexes have long been considered as lead sensitizers due to their ideal photophysical and structural properties [4-6], allowing the attainment of up to $11 \%$ conversion efficiency [7-9]. Very high electron injection quantum yields [10-12] are at the origin of the remarkable success of these sensitizers. Indeed, they exhibit long-lived metal-ligand charge-transfer (MLCT) states that allow the electron injection into the semiconductor conduction band (CB). Electron injection is also further favored by an efficient interfacial electron-hole separation and by their peculiar adsorption geometry [13]. These same characteristics minimize unwanted side-processes such as detrimental charge recombination between the photoanode and the sensitizer. However, ruthenium is a scarce, potentially toxic, and expensive metal, limiting the real-world industrial development. This has motivated the quest for valuable alternatives, and among them, earth-abundant, low-cost, and environmentally friendly d-block metals such as iron [14-16] and copper [17,18] are particularly attractive. Despite an intense MLCT absorption, however, conventional Fe(II) polypyridyl complexes are, unfortunately, characterized by an ultrafast (ca. $100 \mathrm{fs}$ ) deactivation of the MLCT manifold to low-lying metal-centered (MC) states, proceeding via the triplet ${ }^{3} \mathrm{MC}$ and ultimately populating the quintuplet ${ }^{5} \mathrm{~T}_{2}$ state [13,19-22], hence impeding electron injection into the sensitized semiconductor.

The difference in the involved excited-state relaxation pathways between $\mathrm{Ru}-$ and Fe-polypyridine complexes is shown in Figure 1 [23]. In the former case, the metastable MLCT states are populated with a relatively long lifetime due to the absence of competitive relaxation pathways. When they are linked to a photoanode, since the MLCT state energy is high enough, electron injection into $\mathrm{TiO}_{2}$ is favored (Figure 1a). As for Fe-polypyridine complexes, on the other hand, the MC states lie at lower energy than the MLCT ones [24]. This results in the presence of efficient photophysical channels that allow the deactivation of the optically excited ${ }^{1,3}$ MLCT states (Figure 1b). From a light-to-energy conversion point of view, this means that the useful photon energy is available during a much too short time lapse. In other words, intramolecular relaxation rates are much larger than those of functional photochemical processes.

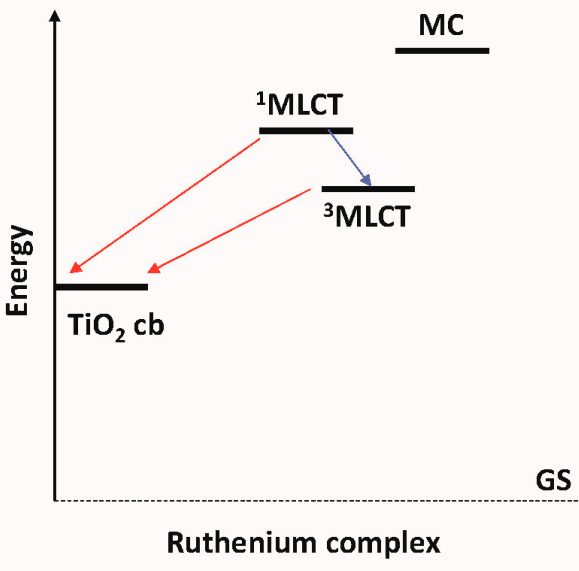

(a)

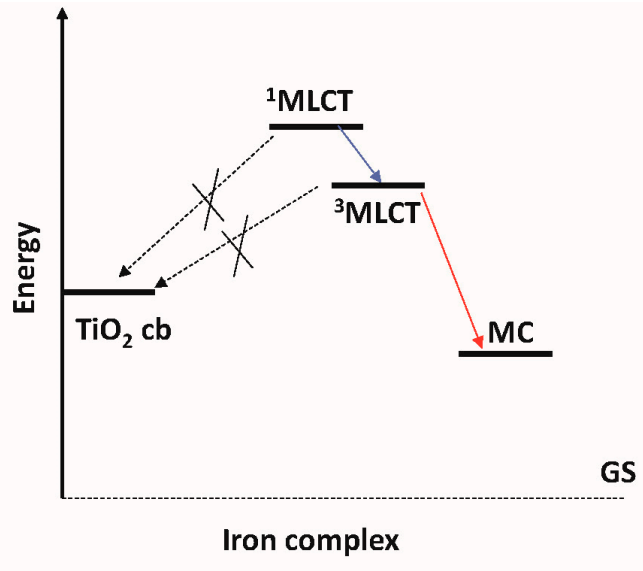

(b)

Figure 1. Energetic diagrams of: (a) Ruthenium polypyridine complexes; (b) Iron polypyridine complexes.

Therefore, the main challenge for further development of Fe-polypyridine complexes applicable in photochemical energy conversion processes is to enhance the lifetime of the ${ }^{1,3}$ MLCT 
manifold by precisely tuning the MLCT and MC potential energy surfaces, and most importantly, their relative positions.

As a first approximation, one can consider that the efficiency of the MLCT to MC relaxation is strongly dependent on the field strength brought by the ligands around the iron center. Indeed, the stronger the ligand-field splitting, the more separated the pseudo $t_{2 g}$ and $e_{g}$ orbitals will be and hence the stronger the MC states' destabilization. On the other hand, the increase of the $\pi$-conjugation of the ligand, and the presence of electron-acceptor group, will generally lower the energy of the MLCT states.

Recently, as shown by Wärnmark and coworkers, N-heterocyclic carbenes (NHC) have been proven to promote notable improvements of ${ }^{3} \mathrm{MLCT}$ lifetimes, thanks to strong $\sigma$-donating effects inducing the destabilization of MC states [25-28]. While no DSSCs have been built from the newly designed complexes, this work has fostered the revival of research towards the development of iron-based sensitizers for DSSCs, which has been almost asleep since the pioneering works by Ferrere using the $\mathrm{Fe}(\mathrm{dcbpy})_{2}(\mathrm{CN})_{2}$ dye [14].

In a different approach, using high-spin ground state halogen-substituted $\mathrm{Fe}(\text { terpy })_{2}$ complexes, it was shown that the ${ }^{5} \mathrm{~T}_{2}$ to ${ }^{5,7} \mathrm{MLCT}$ transition can lead to $\approx 16$ ps excited-state lifetimes, which presents a more than 100-fold increase with respect to traditional Fe-polypyridine complexes [29].

This review is devoted to our group's latest developments in the field of NHC-based Fe(II) photosensitizers and their use in DSSCs. We focus on the synthesis of both homo- and heteroleptic complexes, discuss their photophysical, electrochemical, and computational characterization, and finally, we describe the performance of these complexes as photosensitizers in DSSCs.

\section{Design of Sensitizers}

When designing a potentially efficient iron-based sensitizer, one has to carefully take into account all the operating parameters of the DSSC. In this regard, the energetic levels of the ${ }^{1,3}$ MLCT manifolds have to be adequately positioned to allow the injection of the photogenerated electron into the $\mathrm{CB}$ of the semiconductor (SC). As previously stated, the difference between first-row $\mathrm{Fe}(\mathrm{II})$ and second-row $\mathrm{Ru}$ (II) transition metals stems from the MC energy level, which is much lower for the former. Therefore, although having appropriate MLCT states, favorable electron transfer reactions into the SC typically only take place in $\mathrm{Ru}$ (II) complexes, since MLCT states from Fe(II) complexes undergo an ultrafast depopulation towards the MC states (Figure 1). In order to reverse the position of both MLCT and MC states in $\mathrm{Fe}(\mathrm{II})$ complexes and thus their interstate relaxation processes, special attention has to be paid to the electronic environment of the metal center through the modification of the metal-ligand interaction. To reach this challenging goal, the introduction of strong-field ligands is a powerful tool to raise the energy of the MC levels.

However, the design of a sensitizer for a DSSC must also take into account the global electron transfer process from the sensitizer's excited state, and thus, a $\pi$-accepting site (to assist the extraction of the excited electron density towards the semiconductor) also has to be introduced into the coordination sphere. Moreover, the creation of $\pi$-deficiency is also expected to contribute to lowering the MLCT level. Thus, pyridyl-NHC ligands appear to be ideal candidates by fulfilling the requirements of $\pi$-acceptor (pyridine) and $\sigma$-donor (NHC) features. Importantly, the obtained iron complex must absorb a wide portion of the solar spectrum, especially in the visible region. Furthermore, the contrasting electronic character between the donor NHC units and the acceptor pyridine rings would definitely favor the electron transfer directionality, a critical feature for the performance of the sensitizer under DSSC conditions.

In order to prevent isomeric problems, Wärnmark and coworkers initially described the synthesis of tridentate bis-imidazolium pyridine (L1) as the ligand precursor [25], and the subsequent preparation of homoleptic complex $\mathbf{C 1}$ (Figure 2a). The authors also prepared the terpyridine (tpy) counterpart, namely $\left[\mathrm{Fe}(\mathrm{tpy})_{2}\right]^{2+}$, for comparison reasons (Figure $2 \mathrm{a}$ ). The stronger $\sigma$-donating character of the pyridylcarbene ligand with respect to tpy was nicely evidenced by the lower oxidation potential of the 
complex, which was assigned to $\mathrm{Fe}(\mathrm{II}) / \mathrm{Fe}(\mathrm{III})$ oxidation. Concerning the optical features, the absorption spectra of both $\mathbf{C} 1$ and $\left[\mathrm{Fe}(\mathrm{tpy})_{2}\right]^{2+}$ is shown in Figure $2 \mathrm{~b}$. As can be observed, a notable difference of the MLCT band position was obtained, being $92 \mathrm{~nm}$ blue-shifted for $\mathbf{C 1}$ with respect to the one of $\left[\mathrm{Fe}(\mathrm{tpy})_{2}\right]^{2+}$. Nevertheless, an exceptional increase of the excited-state lifetime of $\mathbf{C 1}$ was achieved. In fact, complex C1 attained a 9-ps MLCT lifetime, while that of [Fe(tpy) $\left.)_{2}\right]^{2+}$ was 145 fs only [30]. Despite the lower covering of the $500-800 \mathrm{~nm}$ window, which is where the solar spectral irradiance is maximum, this result opened up the door for this class of complexes to be employed in PV applications.

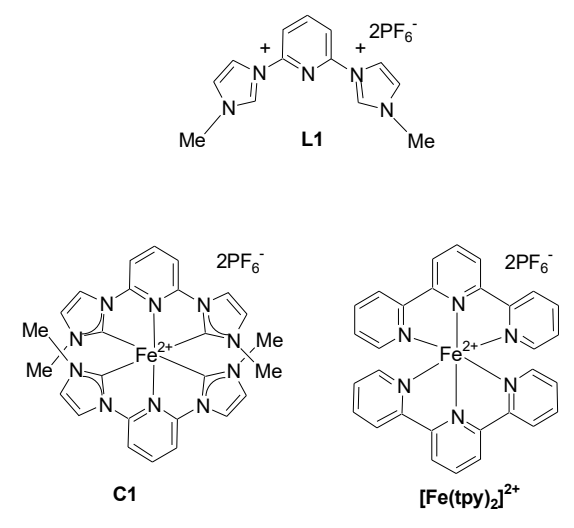

(a)

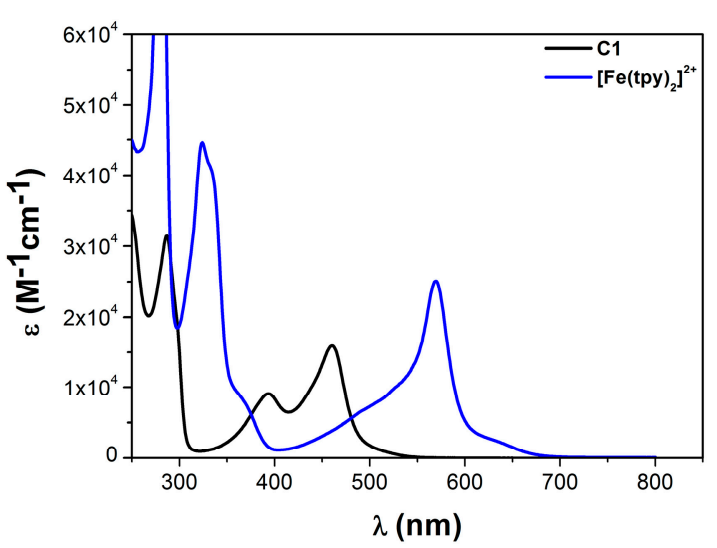

(b)

Figure 2. (a) Structure of the ligand precursor $\mathbf{L 1}$ and complexes $\mathbf{C} 1$ and Fe(tpy) ${ }_{2}$; (b) Comparison of the absorption spectra of $\mathbf{C} 1$ and $\mathrm{Fe}(\mathrm{tpy})_{2}$ complexes in acetonitrile.

Our group has investigated several routes to improve the ${ }^{3}$ MLCT lifetime of Fe-NHC carbenes by chemically modifying the different areas of the ligands. We also examined the ways to shift back the absorption spectra towards longer wavelengths in homoleptic complexes, mostly by a stabilization of both singlet and triplet MLCT manifolds.

\subsection{NHC-Based Homoleptic Complexes}

\subsubsection{Effects of Carboxylic Groups}

We first decided to tune the MLCT state levels by introducing electron-withdrawing groups onto the ligands as in C2 (Scheme 1) [30]. The interest of investigating the effect of carboxylic groups was two-fold: (i) the electron-withdrawing effect was expected to stabilize the MLCT states and thus decrease the MLCT transition gap and red-shift the absorption band; (ii) carboxylic groups also allow further grafting of the sensitizer onto the semiconductor surface.

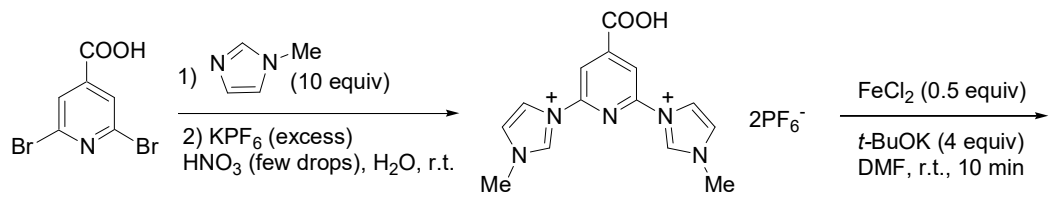

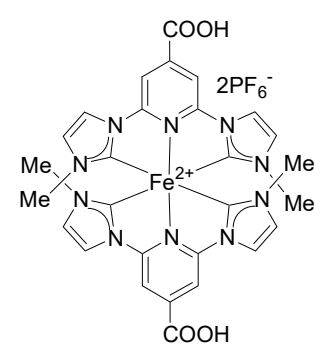

C2

Scheme 1. Synthesis of complex C2. 
In Figure 3, the electronic absorption spectra of pyridine-bis-NHC Fe(II) complexes C1 and C2 are collected. For both complexes, three main bands can be identified. The intense band near $320 \mathrm{~nm}$ corresponds to ligand-based $\pi-\pi^{*}$ transitions. At $360-380 \mathrm{~nm}$, another band is observed that seems to be little affected by the nature of the ligand. On the contrary, the lower energy bands, in the 450-600 nm range, are significantly modified in terms of absorption maxima shifts and band shape. These two bands can be assigned to MLCT transitions. Indeed, the bands at 360-380 nm can be regarded as the charge transfer to NHC moieties $\left[\mathrm{d} \pi(\mathrm{Fe}) \rightarrow \pi^{*}(\mathrm{NHC})\right]$, while the lowest-energy ones represent transfer to the central pyridine $\left[\mathrm{d} \pi(\mathrm{Fe}) \rightarrow \pi^{*}(\mathrm{py})\right]$. As a result, the functionalization of the central pyridine nucleus with a carboxylic group in $\mathrm{C} 2$ promotes a dramatic red-shift of this band (vide infra), whose absorption maximum is shifted from 460 to $520 \mathrm{~nm}$ from C1 to C2, respectively. The cyclic voltammograms of C1 and $\mathrm{C} 2$ confirm these results. The decrease of the electrochemical bandgaps $\left(\Delta \mathrm{E}=\mathrm{E}_{\mathrm{ox}}-\mathrm{E}_{\mathrm{red}}\right)$ from $2.75 \mathrm{eV}$ to $2.20 \mathrm{eV}$ going from $\mathbf{C} 1$ to $\mathbf{C} 2$ indicates that a lower energy is required to operate the metal-ligand charge transfer in C2.



Figure 3. Comparison of electronic absorption of spectra of complexes $\mathbf{C} 1$ and $\mathbf{C} 2$ in air-equilibrated acetonitrile solution at room temperature.

The excited-state lifetimes of the complexes were studied by femtosecond transient absorption spectroscopy (TAS) with $\approx 80 \mathrm{fs}$ time resolution and broadband white-light probing in the $300-700 \mathrm{~nm}$ range, in order to access the full spectra of photoinduced ground state bleach (GSB) and excited-state absorption (ESA). Details are given in ref. [28] and in its Supporting information. A typical set $\Delta \mathrm{A}$ (differential absorbance) data is displayed for C2 in Figure 4a, which shows these spectra for different delay times from -0.2 to $64 \mathrm{ps}$. They reveal GSB as negative signals at 400 and $505 \mathrm{~nm}$ and positive ESA bands peaking in the near-UV (320-360 nm), the blue (420-450), and in the red part of the spectrum $(>580 \mathrm{~nm})$. These three ESA bands are characteristic of the ${ }^{3}$ MLCT state in Fe(II) complexes [24,31]. A detailed analysis of the spectral dynamics allows us to establish the following photoinduced reaction scenario [30]:

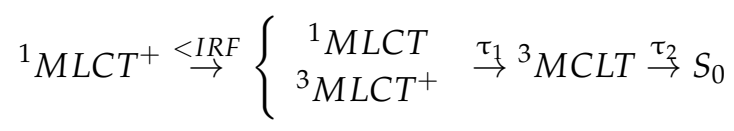

Photoexcitation leads to population of a vibrationally excited ${ }^{1} \mathrm{MLCT}+$ manifold, which relaxes within the experimental time resolution ("<IRF") into a mixture of the vibrationally relaxed ${ }^{1} \mathrm{MLCT}$ and the vibrationally excited ${ }^{3} \mathrm{MLCT}^{+}$triplet [23]. The fast changes of the ESA spectrum, especially for $\lambda>580 \mathrm{~nm}$, reflects a second, slower state of intra- and intermolecular relaxation, occurring on the timescale $\tau_{1}$, which is in the 80-200 fs time range, and leads into the vibrationally relaxed ${ }^{3} \mathrm{MLCT}$ state. Indeed, for delay times longer than 0.3 ps, the spectral shape of the ESA bands is time-invariant. 
Their amplitude decays with the time constant $\tau_{2}$, which is the ${ }^{3}$ MLCT lifetime (Figure $4 b$ ). For C1, we confirm the ${ }^{3} \mathrm{MLCT}$ lifetime of $9.0 \pm 1.0 \mathrm{ps}$ [24] and find $\tau_{2}=16.5 \pm 1.0 \mathrm{ps}$ [28]. The two COOH groups on the central pyridine moiety almost double the excited-state lifetime.

There is no indication for the occurrence of the quintuplet ${ }^{5} \mathrm{~T}_{2}$ state, since the latter is characterized by a $20 \mathrm{~nm}$ narrow ESA at $355 \mathrm{~nm}$ for Fe(II)-polypyridine complexes [28]. In a recent work on $\left[\mathrm{Fe}\left(2,2^{\prime} \text {-bipyridine }\right)_{2}(\mathrm{CN})_{2}\right]$ complexes, the relaxation of ${ }^{3} \mathrm{MLCT}$ into metal-centered triplet states ${ }^{3} \mathrm{MC}$ with several-picosecond lifetimes was revealed [32,33]. This should lead, as for the case of the ${ }^{5} \mathrm{~T}_{2}$ state in $\mathrm{Fe}\left(2,2^{\prime} \text {-bipyridine }\right)_{3}$, to a GSB recovery retarded with respect to the ${ }^{3}$ MLCT ESA decay. As we do not find any indication for this-both kinetics perfectly overlap for C1 and C2 (Figure $4 b$ ) - we conclude that a possible population of ${ }^{3} \mathrm{MC}$ has to have an order-of-magnitude-shorter lifetime than for ${ }^{3} \mathrm{MLCT}$, and therefore a negligible concentration that goes unnoticed in the TAS data.

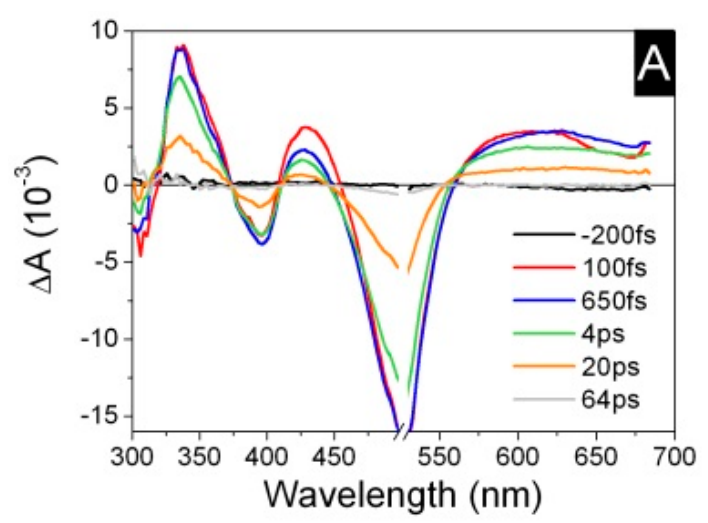

(a)

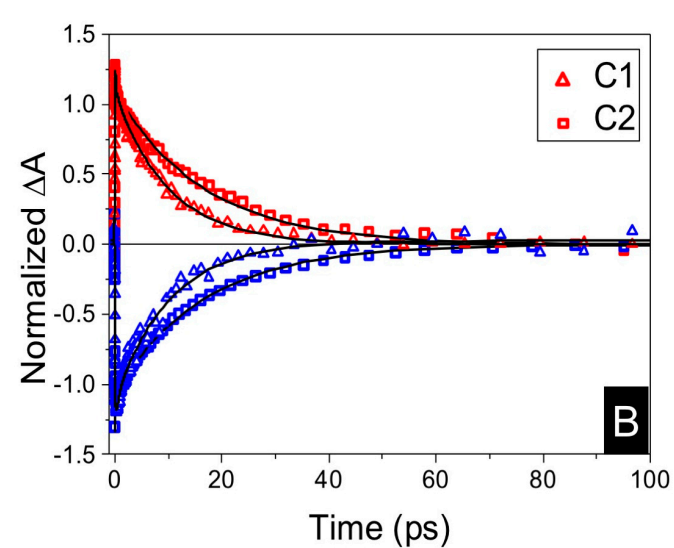

(b)

Figure 4. Femtosecond absorption data revealing the long-lived ${ }^{3}$ MLCT states. (a) Time-resolved spectra of C2 in acetonitrile. Data in the $490-530 \mathrm{~nm}$ region are missed out due to pump laser scatter. (b) Comparison of the ESA (red) and GSB (blue) kinetic traces of complexes $\mathbf{C} \mathbf{1}$ and $\mathbf{C 2}$. The $\mathrm{COOH}$ groups in C2 almost double the excited-state lifetime ( $\left.\tau_{2}=16.5 \mathrm{ps}\right)$. Note that ESA and GSB decay in parallel. Figure $4 \mathrm{a}$ is reprinted with permission from Ref. [30] (Copyright 2015 WILEY-VCH Verlag GmbH \& Co. KGaA, Weinheim).

The photophysical properties of $\mathbf{C} 1$ and $\mathbf{C} 2$ were also theoretically investigated using density functional theory (DFT) and the time-dependent (TD)-DFT techniques, employing the Hamprecht-Cohen-Tozer-Handy (HCTH) exchange and correlation functional [30]. The simulated absorption spectra are in good agreement with the experimental recordings. The ${ }^{1}$ MLCT states were further characterized at the Franck-Condon region by computing the natural transition orbitals (NTOs, see Figure 5), which provide excited-state descriptions based on only one (or at maximum, two) couples of orbitals [30], confirming the MLCT nature of the lowest-energy optical bands at visible wavelengths as being recorded experimentally (Figure 3). The excited-state decay of the triplet states was studied based on the relative energy of the ${ }^{3} \mathrm{MLCT}$ and ${ }^{3} \mathrm{MC}$ states at their corresponding equilibrium geometry and the energy difference $(\Delta E)$ between these two structures. For $\mathbf{C} 1$, the ${ }^{3} \mathrm{MC}$ minimum lies $0.73 \mathrm{eV}$ below the ${ }^{3} \mathrm{MLCT}$ equilibrium geometry, whereas both triplet states are almost degenerate $(\Delta E=0.08 \mathrm{eV}$ ) in the case of $\mathbf{C 2}$ (see Table 1). These significant differences actually support the faster decay of the ${ }^{3}$ MLCT state of $\mathbf{C 1}\left(\tau_{2} \sim 9.5 \pm 1.0 \mathrm{ps}\right)$ as compared to C2 $\left(\tau_{2} \sim 16.5 \pm 1.0 \mathrm{ps}\right)$. The differences found in the relative MLCT and MC energies can be ascribed to the effect of the $\mathrm{COOH}$ group, only present in $\mathbf{C 2}$, in the electronic structure of the ${ }^{3} \mathrm{MLCT}$ states. Thus, the electron-withdrawing character of this substituent is expected to stabilize the electron density localized over the aromatic rings, in global agreement with the observed and calculated red-shift of the MLCT absorption band. This explanation is consistent with the negligible impact of the $\mathrm{COOH}$ 
substitution in the ${ }^{3} \mathrm{MC}$ energies, since the excitation in the latter states is entirely localized in the metal atom. As a result, the ${ }^{3} \mathrm{MLCT}$ state has a lower energy in $\mathrm{C} 2$ as compared to $\mathbf{C} 1$, leading to quasi-degenerated ${ }^{3} \mathrm{MLCT}$ and ${ }^{3} \mathrm{MC}$ equilibrium geometries in the former complex, and hence to the important increase of excited-state lifetime.

\begin{tabular}{|c|c|c|c|c|}
\hline$\lambda[\mathrm{nm}]$ & $f$ & $\mathrm{~s}^{*} \mathrm{~s}$ & oNTO & vNTO \\
\hline
\end{tabular}

$543 \quad 0.27$

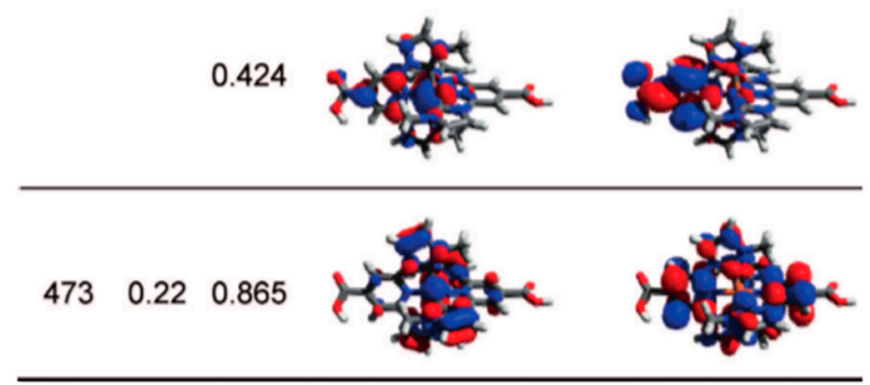

Figure 5. Natural transition orbitals (NTOs) isodensity surface of $\mathbf{C} 2$ describing the ${ }^{1}$ MLCT states at the Franck-Condon region. $\lambda$ is the absorption wavelength, $f$ stands for oscillator strength, $\mathrm{s}^{*} \mathrm{~s}$ refers to the weight of the NTO couples, and oNTO and vNTO stand for "occupied" and "virtual" NTO, respectively. Reprinted with permission from Ref. [30] (Copyright (C 2015 WILEY-VCH Verlag GmbH \& Co. KGaA, Weinheim).

Table 1. Energy difference $(\Delta E)$ between the ${ }^{3} \mathrm{MLCT}$ and the ${ }^{3} \mathrm{MC}$ states at their corresponding equilibrium structure, calculated as $\Delta E=E\left({ }^{3} \mathrm{MLCT}\right)-E\left({ }^{3} \mathrm{MC}\right)$ for the $\mathbf{C 1}-\mathbf{C} 4$ compounds computed with the TD-DFT theoretical method. The ${ }^{3}$ MLCT lifetimes recorded experimentally are also shown.

\begin{tabular}{ccc}
\hline Complex & $\Delta E(\mathrm{eV})$ & ${ }^{3}$ MLCT Lifetime (ps) \\
\hline C1 & $0.78^{1}$ & $9.5 \pm 1.0^{1}$ \\
C2 & $0.08^{1}$ & $16.5 \pm 1.0^{1}$ \\
C3 & - & $16.4 \pm 0.4^{2}$ \\
C4 & $-0.12^{2}$ & $26 \pm 1^{2}$ \\
\hline \multicolumn{3}{c}{}
\end{tabular}

This initial promising result prompted us to modify the NHC coordination site. In order to introduce additional $\pi$-accepting character on the NHC side and thus provide additional stabilization of the MLCT states via improved conjugation with the pyridines, the imidazolylidene (Im) moieties were substituted by benzimidazolylidene ones (BIm) [34]. The resulting complexes C 3 and C4 were prepared following Scheme 2.

As can be seen in Figure 6a, C3 and C4 exhibited the same absorption features as $\mathbf{C} 1$ and $\mathbf{C 2}$. When comparing both sets of complexes, it is interesting to note that the bands in the 360-390 nm range related to the Fe-carbene MLCT $\left[\mathrm{d} \pi(\mathrm{Fe}) \rightarrow \pi^{*}(\mathrm{NHC})\right]$ transition [30] are strongly affected in energy when switching from imidazolylidene ( $\mathrm{Im}$ ) to benzimidazolylidene (BIm). Indeed, the absorption maxima for complexes $\mathbf{C} 3$ and $\mathbf{C} 4$ are blue-shifted by $20 \mathrm{~nm}$ compared with those of $\mathbf{C} \mathbf{1}$ and $\mathbf{C} 2$. This blue-shift is clearly in agreement with the electron-accepting effect of the phenyl ring in BIm, that must stabilize the $t_{2 g}$ system upon $\pi$-back-donation from the iron centre. In line with this conclusion, cyclic voltammetry measurements (Table 1) showed an increase in the $\mathrm{Fe}(\mathrm{II}) / \mathrm{Fe}$ (III) oxidation potential (vs. SCE) (SCE = Saturated Calomel Electrode) going from C1 (0.8 V) and C2 
(0.85 V) complexes to C3 (1.04 V) and C4 (1.13 V) [34]. The more-stabilized metal orbitals in C3 and C4 concomitantly affected the energy of the Fe-pyridine MLCT $\left[\mathrm{d} \pi(\mathrm{Fe}) \rightarrow \pi^{*}(\mathrm{py})\right]$ bands, being also blue-shifted with respect to those of $\mathbf{C} 1$ and $\mathbf{C} 2$.
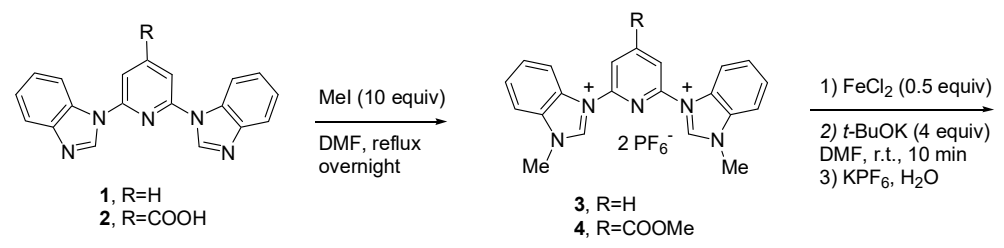
3) $\mathrm{KPF}_{6}, \mathrm{H}_{2} \mathrm{O}$

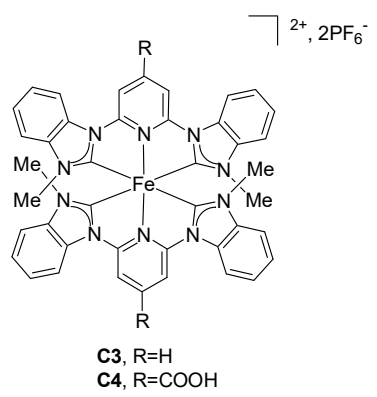

Scheme 2. Synthesis of complexes C3 and C4.

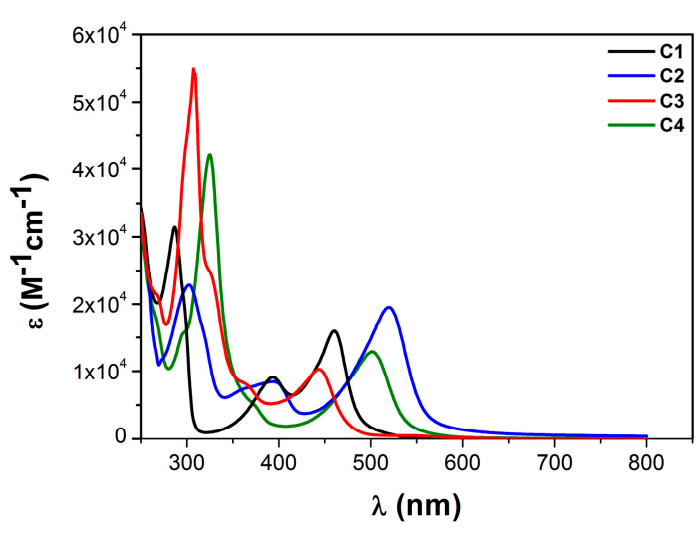

(a)

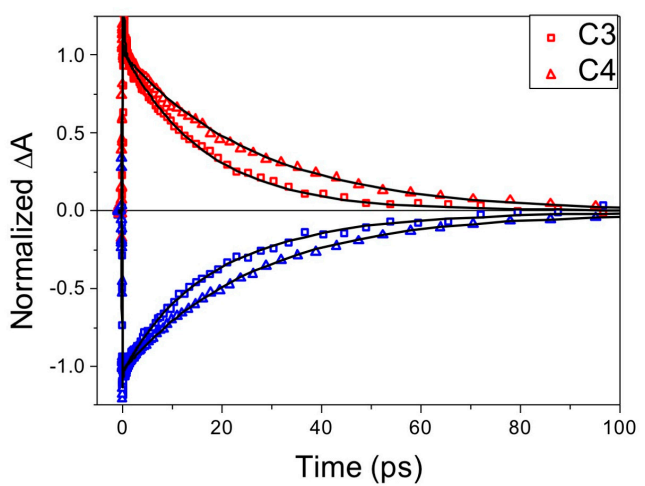

(b)

Figure 6. (a) Absorption spectra of complexes C1-C4 in air-equilibrated acetonitrile solution at room temperature. (b) Right: GSB- and ESA-normalized kinetic traces of the BIm-containing complexes C3 and $\mathrm{C} 4$ in acetonitrile.

Cyclic voltammetry also shows the effects of the phenyl groups on the reduction potential, and thus the MLCT states. This substitution stabilizes the MLCT by $0.15 \mathrm{eV}$ (C3 vs. C1) and $0.12 \mathrm{eV}$ for C4 vs. C2, probably due to a better conjugation between the pyridine and the NHC [34]. The so-reduced ${ }^{3}$ MLCT- ${ }^{3}$ MC energy gap is held responsible for the increased lifetime of $\mathbf{C} 3$.

Finally, as already observed for the Im-based complex C2 [34], the functionalization of the central pyridine ring with the carboxylic groups promotes a notable red-shift of the band at lowest energy in BIm-based complexes moving from 440 to $500 \mathrm{~nm}$; i.e., from C3 to C4, respectively. Analogously, such a red-shift is due to the stabilization of the MLCT states by the electron-withdrawing effect of the carboxylic group on the ligand-conjugated $\pi$ system, as shown by downshifts of $\approx 0.6 \mathrm{eV}$ of the reduction potential [34].

The BIm leads to a significant lengthening of the ${ }^{3}$ MLCT lifetime (Figure $6 \mathrm{~b}$ ). We find $\tau_{2}=16.4 \pm 0.5$ and $26.0 \pm 0.5 \mathrm{ps}$ for $\mathrm{C} 3$ and $\mathrm{C} 4$, respectively. Again, addition of the two $\mathrm{COOH}$ groups leads to a significant enhancement of the ${ }^{3} \mathrm{MLCT}$ lifetime [30].

The excited-state properties of C4 were further analyzed by means of DFT and TD-DFT [34]. Inspection of the NTOs computed at the Franck-Condon region confirmed the MLCT nature of the lowest-energy band peaking in the visible region (see Figure 7). The electronic excitation mainly occurs from the iron atom to the two pyridyl moieties, and to some extent, also involving the $\mathrm{COOH}$ substituents. This latter finding suggests a favorable charge injection into a semiconductor like $\mathrm{TiO}_{2}$. The decay of the triplet states of $\mathbf{C} 4$ was further assessed computing the ${ }^{3} \mathrm{MLCT}$ and ${ }^{3} \mathrm{MC}$ equilibrium 
structures and comparing their relative energies (see Table 1). In contrast to $\mathbf{C 2}$, in which the ${ }^{3} \mathrm{MC}$ lies $0.08 \mathrm{eV}$ below the ${ }^{3} \mathrm{MLCT}$ minimum, in C4, the energy order is inverted and the ${ }^{3} \mathrm{MC}$ equilibrium structure lies $0.12 \mathrm{eV}$ above the ${ }^{3} \mathrm{MLCT}$ minimum, therefore supporting the observed longer ${ }^{3} \mathrm{MLCT}$ lifetimes up to $\sim 26 \pm 1$ ps. C4 should hence be considered as the first example of a synthetically available iron complex presenting a ${ }^{3} \mathrm{MLCT} /{ }^{3} \mathrm{MC}$ inversion.

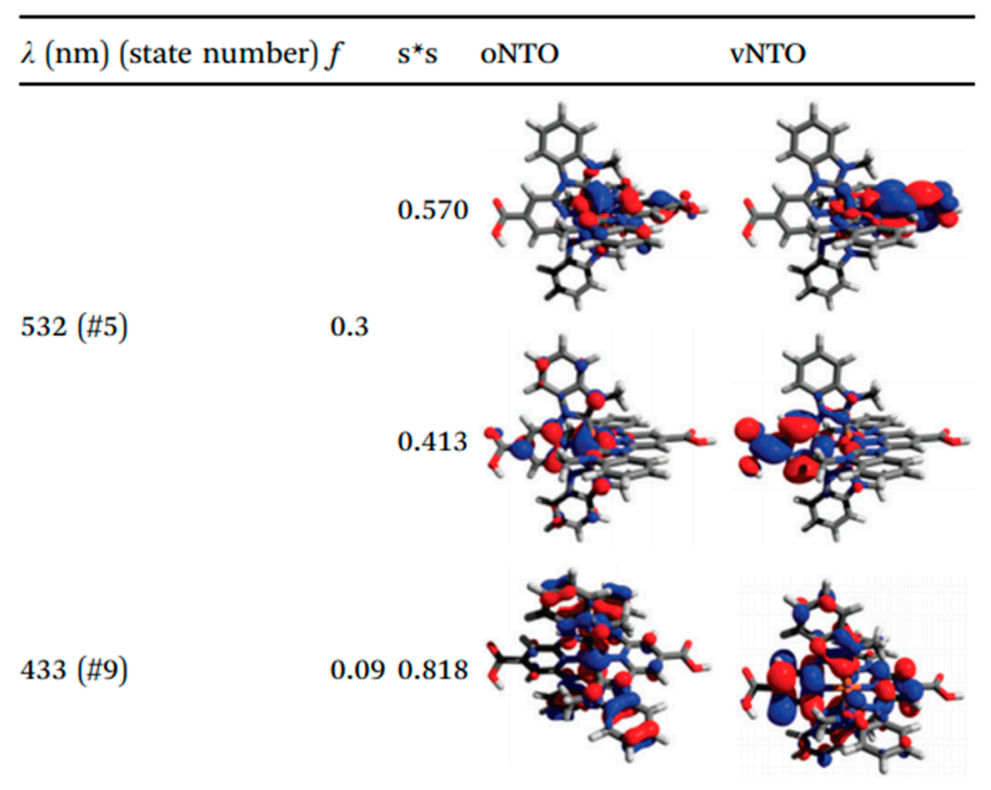

Figure 7. NTO isodensity surface of $\mathbf{C} 4$ describing the ${ }^{1}$ MLCT states at the Franck-Condon region. $\lambda$ is the absorption wavelength, $f$ stands for oscillator strength, $\mathrm{s}^{*} \mathrm{~s}$ refers to the weight of the NTO couples, and oNTO and vNTO stand for "occupied" and "virtual" NTO, respectively. Reproduced from Ref. [34] with permission from the PCCP Owner Societies.

The effect of the number of carboxylic groups on photophysical properties was also examined. To investigate this, complex $\mathrm{C} 5$ [35] was prepared bearing the $\mathrm{COOH}$ group on only one ligand (see Scheme 3).<smiles></smiles>

1)<smiles>Cn1cc[n+](-c2cccc(-n3cc[n+](C)c3)n2)c1</smiles>

2) tBuOK (4 equiv)

3) $\mathrm{KPF}_{6}, \mathrm{HNO}_{3}, \mathrm{H}_{2} \mathrm{O}$

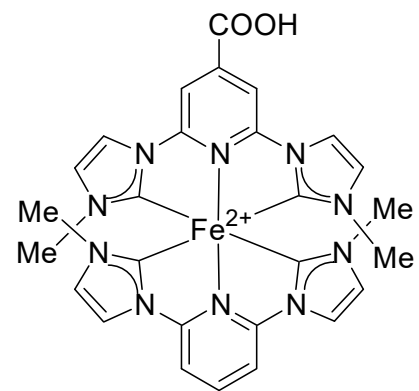

C5

Scheme 3. Preparation of monocarboxylic complex C5.

In contrast to $\mathbf{C} \mathbf{1}$ and $\mathbf{C 2}$, absorption spectra of complex $\mathbf{C} 5$ exhibit one additional band in the visible region, that is, at $440 \mathrm{~nm}$, that has no correspondence with those of the former (Figure 8a). This band can be nicely assigned to the charge-transfer transition between the metal and the pyridine ring without the carboxylic group. The lowest-energy band at $510 \mathrm{~nm}$ is attributed to a MLCT transition 
involving the pyridine bearing the carboxylic group. In comparison with previously described complexes here, the band at $380 \mathrm{~nm}$ should be considered as the signature of the Fe-carbene MLCT transition, which is not affected by the presence of the carboxylic group.



(a)

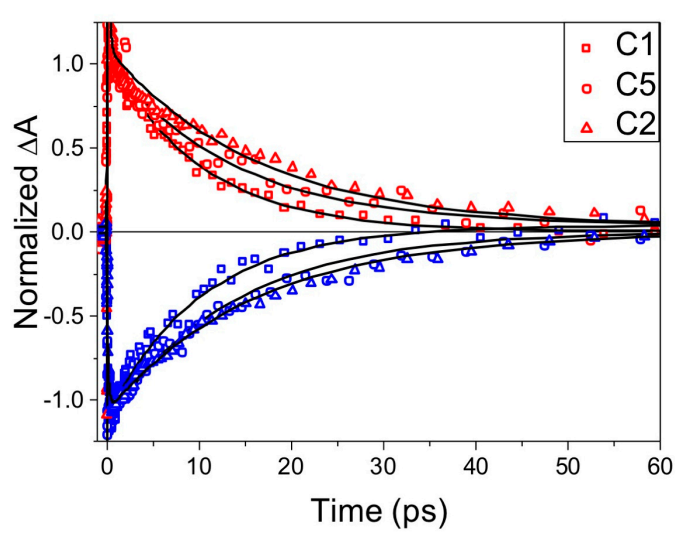

(b)

Figure 8. (a) Absorption spectra of $\mathbf{C 1}, \mathbf{C} 2$, and $\mathbf{C} 5$ in air-equilibrated acetonitrile solution at room temperature. (b) GSB (blue) and ESA (red) kinetics characterizing the ${ }^{3}$ MLCT lifetimes in the three compounds.

The excited-state lifetimes of $\mathbf{C 1}, \mathbf{C} 2$, and $\mathbf{C} 5$ in acetonitrile are reported in Figure 8b. The excitation wavelength is adjusted to be slightly longer than the absorption maximum for all complexes. As for the other complexes, C5 follows the sequential excited-state relaxation scenario (see Equation (1)). We find an intermediate lifetime for $\mathbf{C} 5$, which is $\tau_{2}=14.0 \pm 1.0$ ps, i.e., slightly shorter than that of C2. Excitation is selective in the low-energy transition related to the $\mathrm{COOH}$-substituted NHC ligand. The absorption spectrum indicates a $45-50 \mathrm{meV}$ upshift of the ${ }^{1} \mathrm{MLCT}$ transition in C5 with respect to $\mathrm{C2}$, and the ${ }^{3} \mathrm{MLCT}$ level can be expected to follow the same trend, so that the energy difference $\Delta \mathrm{E}$ increases. $\mathbf{C} 5$ thus follows the same trend as the other complexes: $\tau_{2}$ shortens for an increasing value of $\Delta \mathrm{E}$ (Table 1).

Taken together, complexes $\mathbf{C} \mathbf{1}$ to $\mathbf{C} 5$ underscore the action of two effects induced by ligand design: (a) lowering of the MLCT energies due to electron-accepting groups ( $\mathbf{C 2}, \mathbf{C 4}$, and $\mathbf{C 5})$ and (b) an additional downshift of the MLCT states, most probably due to an increased $\pi$-back-donation (C3 vs. C1).

\subsubsection{Effects of Alkyl Substituents}

Wärnmark et al. [25] reported that the introduction of a bulky t-butyl group on the carbenic part enhances the $\mathrm{Fe}-\mathrm{C}(\mathrm{NHC})$ bond length in the ground state reducing the $\sigma$-donor strength, and thus leading to an SCO-type behavior with a $0.3 \mathrm{ps}$ lifetime for the ${ }^{3} \mathrm{MLCT}$. From the excited-state relaxation perspective, it is well known that the elongation of the Fe-ligand distance is a critical step in the spin cross-over process, and consequently, also for the MLCT/MC deactivation [27]. This is in line with the simple interpretation of the iron-based MC states as involving the population of the $e_{g}$ (i.e., antibonding orbitals). In this context, the modification of the alkyl substituents on the carbene moiety may be a way to counteract the deactivation processes, and hence, increase MLCT lifetimes. We have examined the effect of the chain length of the alkyl substituent by switching from methyl to a linear hexyl chain. Complexes C8 and C9 have been prepared by reaction of the appropriate imidazolium salts with iron(II) chloride under basic conditions (see Scheme 4). 
<smiles>O=[PH+]Cn1cc[n+](-c2cccc(-[n+]3ccn(C(=O)O)c3)n2)c1</smiles><smiles>O=[PH2+]Cn1c[n+](-c2cccc(-[n+]3cn(C=[Zn])c4ccccc43)n2)c2ccccc21</smiles>

1) $\mathrm{FeCl}_{2}$ (0.5 equiv) DMF, r.t., $10 \mathrm{~min}$

3) $\mathrm{KPF}_{6}, \mathrm{H}_{2} \mathrm{O}$

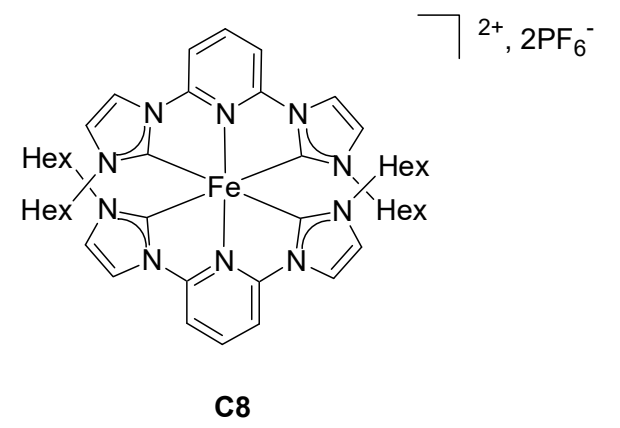

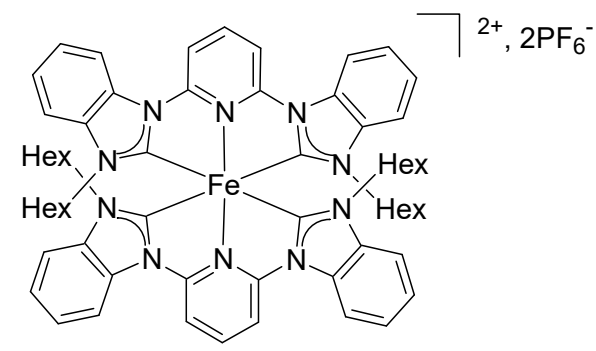

C9

Scheme 4. Synthesis of C8 and C9.

As expected, the absorption spectra of $\mathbf{C} 1$ and $\mathbf{C 8}$ are almost identical (Figure 9), both for the pyridine- and the imidazole-related transitions. Indeed, the alkyl side chains are not electronically conjugated with either of the two moieties. Comparison of $\mathbf{C} 3$ and $\mathbf{C 9}$, however, reveals a splitting of the pyridine transition, by the appearance of a shoulder in the spectrum of C9 at $410 \mathrm{~nm}$ and broadening of the low-energy tail. This indicates some interaction of the hexyl chain with the pyridine moiety. In any case, the ${ }^{3}$ MLCT lifetimes were determined as for the other complexes by excitation of the lowest-energy Fe-pyridine transition. Figure $9 \mathrm{~b}$ shows the effect of the side-chain substitution for C8, which displays a longer $\tau_{2}$ than C1 (12.0 $\left.\pm 1.0 \mathrm{ps}\right)$. A similar $20 \%$ increase of the ${ }^{3}$ MLCT lifetime is observed for C9, $\tau_{2}=19.5 \pm 1.0 \mathrm{ps}$, in comparison with C3. The trend goes in the right direction, but it is unclear whether these relatively small improvements are due to the postulated increase of the Fe-ligand bond rigidity or shielding effects against solvent quenching, since we are lacking structural data for these compounds.

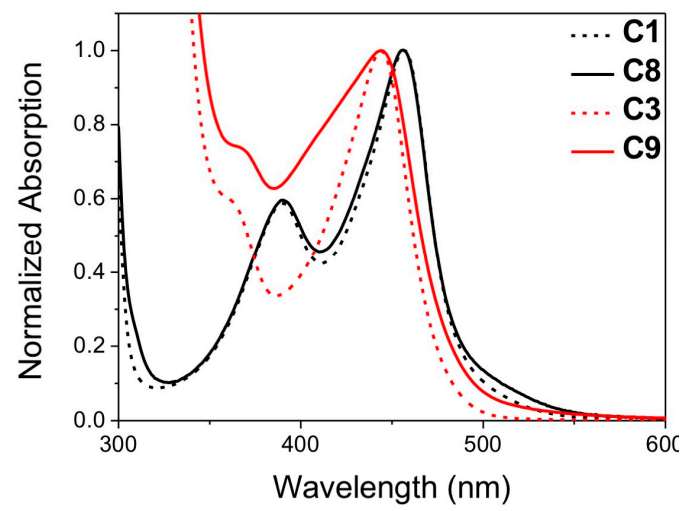

(a)

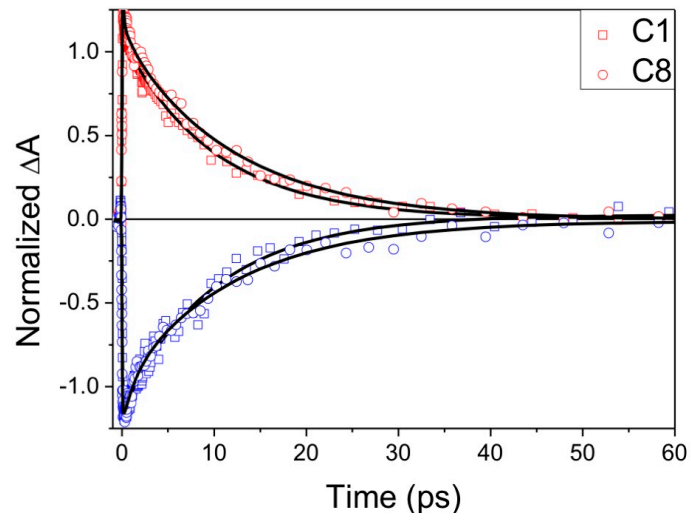

(b)

Figure 9. Effect of replacing the methyl by a hexyl side chain on the carbene moiety (Scheme 4): (a) Normalized ground-state absorption spectra; (b) Normalized kinetic traces of the GSB and ESA of C1 and C8 in acetonitrile. 


\subsubsection{Effects of NHC Counts}

From the previous examples, it clearly appears that the strong $\sigma$-donating effect brought by the NHCs, along with varying contributions of $\pi$-accepting effects, play a fundamental role in the modulation of the MLCT lifetimes. Hence, we decided to investigate the influence of the number of carbenic moieties on the iron complexes' photophysical properties (unpublished results). Thus, complex C10, bearing only two carbene-Fe bonds, and not four as in the above examples, was prepared from a bipyridine-imidazolylidene (bpy-Im) ligand (Scheme 5).



Scheme 5. Synthesis of C10.

The UV-vis spectrum of $\mathbf{C 1 0}$ is depicted in Figure 10a together with those of C1. Although possessing intense high-energy $\pi-\pi^{*}$ bands, the transitions within the visible range are less intense for C10 than for C1. At ca. $400 \mathrm{~nm}$, the band corresponding to the Fe-NHC MLCT transition can be identified, which is comparable with those of $\mathbf{C} \mathbf{1}$. However, the lowest-energy band associated with the Fe-bpy MLCT transition is considerably red-shifted up to $565 \mathrm{~nm}$. This result can be explained in terms of low-lying $\pi^{*}$ states of the bpy unit, together with less stabilized metal orbitals as evidenced by cyclic voltammetry. The oxidation potential associated to the redox couple $\mathrm{Fe}(\mathrm{II}) / \mathrm{Fe}(\mathrm{III})(0.84 \mathrm{~V} / \mathrm{SCE})$ is slightly more positive than for $\mathbf{C} \mathbf{1}$ bearing four NHC moieties. On the negative side, two reversible waves were observed at -1.35 and $-1.62 \mathrm{~V} / \mathrm{SCE}$. In contrast, for C1, the first injection of an electron in the ligand is dramatically more negative ( $\left.\mathrm{E}_{\mathrm{red} 1}=-1.95 \mathrm{~V} / \mathrm{SCE}\right)$. This comparison suggests that the injected electron is more easily delocalized in the bipyridine moiety than in the central pyridine bearing the two carbene groups.

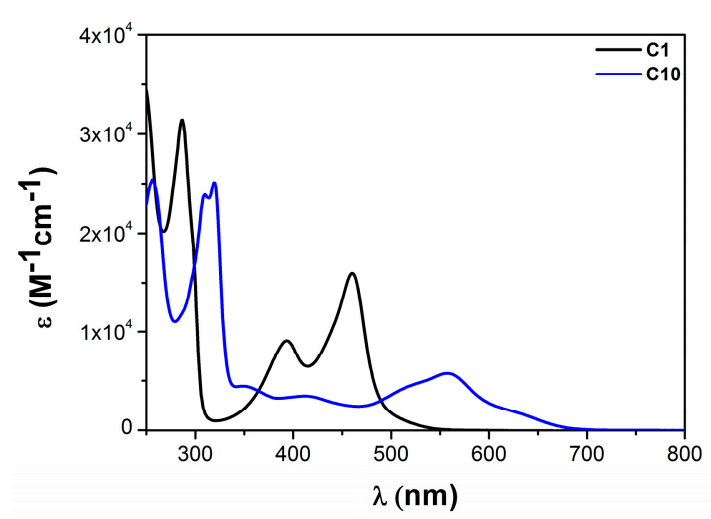

(a)

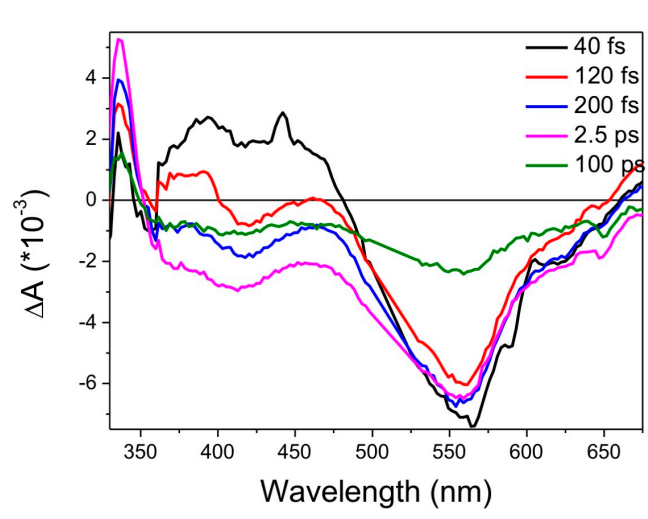

(b)

Figure 10. Photophysics of the two-carbene compound C10. (a) Comparison of the extinction coefficients of compounds C1 (black) and C10 (blue) in acetonitrile. (b) Transient absorption spectra under $515 \mathrm{~nm}$ excitation of C10 in acetonitrile. Data in the 490-530 nm region show excessive noise due to pump laser scatter and are replaced by a straight line. 
From the TAS experiments, it turns out that $\mathbf{C} 10$ is a photoinduced ultrafast spin crossover complex (SCO) since the population of ${ }^{5} \mathrm{~T}_{2}$ occurs within $\approx 0.5 \mathrm{ps}$. This is clearly observed in the time-resolved differential $\Delta \mathrm{A}(\mathrm{t})$ spectra in acetonitrile upon excitation at $515 \mathrm{~nm}$ (Figure 10b), by the ultrafast sub-100-fs decay of the MLCT ESA in the 400-600 nm range and the concomitant rise of the narrow photoinduced absorption (PIA) at $330 \mathrm{~nm}$ characteristic of metal-centered ${ }^{5} \mathrm{~T}_{2}$ for time delays $<0.5 \mathrm{ps}$ [25]. The energy of this PIA is almost identical to that of ${ }^{5} \mathrm{~T}_{2}$ in $\mathrm{Fe}(\mathrm{bpy})_{3}$, meaning that it is situated only 0.5-0.6 eV above $S_{0}$ [36]. We recall here that ${ }^{5} \mathrm{~T}_{2}$ is thus too low in energy to serve for electron injection in the $\mathrm{CB}$ of $\mathrm{TiO}_{2}$. At later times, only the latter PIA remains and the visible part of the spectrum is dominated by GSB. Both signals decay with a 100 ps lifetime, indicating electronic relaxation from ${ }^{5} \mathrm{~T}_{2}$ back to the ground state. A detailed global fitting analysis of the data is performed, providing very good agreement with the experimental kinetic traces (Figure 11).

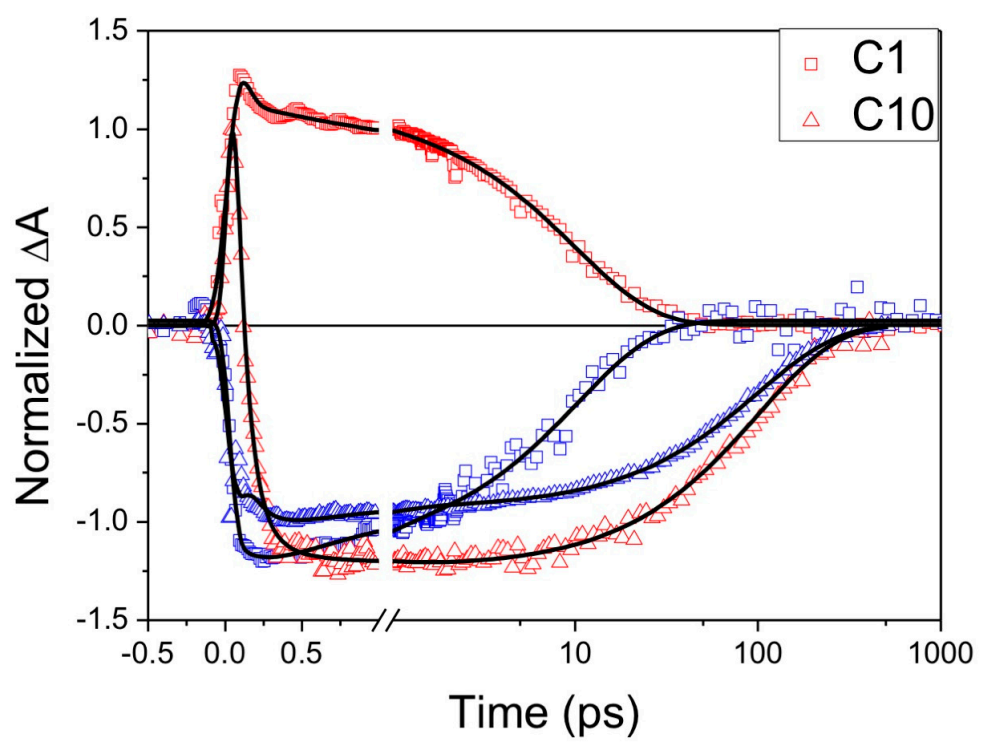

Figure 11. Comparison of the normalized kinetic traces of $\mathbf{C} \mathbf{1}$ and $\mathbf{C 1 0}$ probed at $400 \mathrm{~nm}$ (ESA, red) and $545 \mathrm{~nm}$ (GSB, blue).

It reveals a sequential electronic relaxation scenario, which can be summarized as:

$$
{ }^{1} M L C T^{+} \stackrel{<I R F}{\longrightarrow}\left\{\begin{array}{c}
{ }^{1} M L C T \\
{ }^{3} M L C T^{+}
\end{array} \stackrel{120 \mathrm{fs}}{\longrightarrow} T_{2}^{+} \stackrel{0.5 \mathrm{ps}}{\longrightarrow} T_{2} \stackrel{100 \mathrm{ps}}{\longrightarrow} S_{0}\right.
$$

As for the above complex, the photoexcited ${ }^{1}$ MLCT relaxes vibrationally and into the ${ }^{3}$ MLCT manifold on a non-resolved ultrafast timescale ( $<\mathrm{IRF}$ ), giving rise to the early broad ESA in the visible part of the spectrum. From there, formation of the vibrationally excited quintuplet state is observed with a 120 fs lifetime, slightly slower but in agreement with the sub-100 fs lifetimes reported for $\mathrm{Fe}\left(2,2^{\prime} \text {-bipyridine }\right)_{3}$ [24]. Small spectral shifts occur on a 0.5 ps timescale (not shown), which are consistent with vibrational cooling. The ${ }^{5} \mathrm{~T}_{2}$ state then recombines into the singlet ground state relatively fast, within 100 ps.

These observations complete the TAS data reported by Bauer and coworkers for the same complex [37], since they probe the characteristic near-UV absorption of ${ }^{5} \mathrm{~T}_{2}$. Here, the initial relaxation scenario and formation time is analyzed in more detail. The same authors studied also a heteroleptic compound with tridentate ligands, bearing three carbene bonds (compound 3 in Ref. [37]). The additional carbene bond leads to a longer 3.6 ps lifetime of the ${ }^{3}$ MLCT state, limited by the relaxation into an unidentified MC state, which is relatively short-lived (32 ps) [37]. This work therefore demonstrates that for tridentate ligands made of pyridine and imidazole moieties, 
a minimum of four carbene bonds is needed in order to avoid the ${ }^{3}$ MLCT-quenching SCO process. The question remains whether an increased $\pi$-back-donating character, as implemented with the BIm ligand, or increased bite angle could sufficiently increase the ${ }^{3}$ MLCT lifetime in a three-carbene heteroleptic complex.

\subsection{Heteroleptic Complexes}

Taking into account the excellent absorption of $\left[\mathrm{Fe}(\mathrm{tpy})_{2}\right]^{2+}$ in the $500-600 \mathrm{~nm}$ window, the mixing of tpy and py-bis( $(\mathrm{Im})$ ligands was firstly investigated for the possibility of combining good spectral coverage and enhanced lifetime, respectively. Different terpyridine ligands were proposed, such as pytpy, since it offered an additional electronic tuning via its protonation [38]. The ligands were prepared according to the literature (see details in ref. [38]), and the complexes were synthesized following the strategy depicted in Scheme 6.

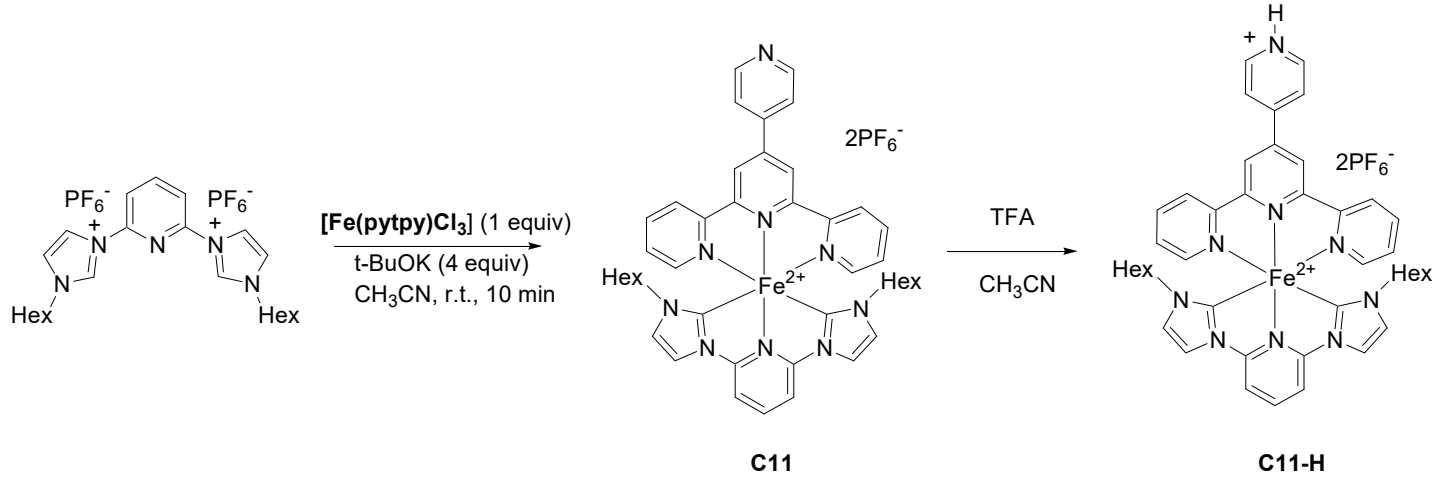

Scheme 6. Synthesis of complex C11 and its protonated form C11-H.

The absorption spectra of homoleptic C8 and heteroleptic C11 are shown in Figure 12a. As can be observed, replacement of one py-bis(Im) ligand in C9 by a tpy ligand in C11 results in a noticeable bathochromic shift of $60 \mathrm{~nm}$ of the two MLCT transition bands in the visible domain, offering a wide absorption domain with nearly constant intensity in the 500-580 nm range. Furthermore, the protonation of the pyridine substituent in $\mathbf{C 1 1}-\mathbf{H}$, and the concomitant increase of electron-accepting character, had a marked effect on the absorption spectrum (see Figure 12b). Indeed, the $560 \mathrm{~nm}$ band in C11 was red-shifted up to $590 \mathrm{~nm}$ due to protonation, extending the visible light harvesting capacity of C11-H from 450 to $650 \mathrm{~nm}$. Importantly, the carbene-containing complex was found to be stable under acidic conditions, which validated our strategy to shift the absorption towards longer wavelengths upon replacing one py-bis(Im) ligand by a pytpy ligand.

Cyclic voltammetry also clearly showed the influence of the pytpy ligand. In fact, while for the homoleptic iron complex $\mathrm{C} 8$, the reversible $\mathrm{Fe}(\mathrm{II}) / \mathrm{Fe}(\mathrm{III})$ oxidation process occurred at $0.41 \mathrm{~V}$ (vs. SCE), $\mathrm{C11}$ led to an oxidation potential of $0.54 \mathrm{~V}$. The protonated form C11-H exhibited a reversible Fe(II) oxidation at a slightly more positive potential $\left(\Delta E_{\frac{1}{2}}=0.02 \mathrm{~V}\right)$ as a result of the formation of the positive charge on the pyridine nitrogen that increased the withdrawing effect on the central metal.

From a theoretical standpoint, the NTOs of the alkyl-substituted C8, C11, and C11-H complexes were computed to understand the differences in the absorption properties observed experimentally [38]. Figure 13 shows the NTO isodensity surfaces for the optically active states of those compounds at the Franck-Condon region. The homoleptic $\mathbf{C} 8$ complex shows a bright ${ }^{1} \mathrm{MLCT}$ state at $449 \mathrm{~nm}$, in which the two oNTOs (i.e., the hole orbitals) are mainly centered on the iron atom, even though non-negligible electron density is also found delocalized over the ligand moieties. This implies that part of the electron density of the aromatic rings is also redistributed after excitation. The NTO analysis also revealed that such electronic redistribution takes place over the two ligands due to symmetry reasons. In contrast, the heteroleptic complex C11 has two bright ${ }^{1}$ MLCT states in the visible region (457 and $546 \mathrm{~nm}$ ), 
in agreement with the experimental data, where these transitions are observed at 505 and $560 \mathrm{~nm}$. In these low-energy MLCT absorptions, the electron density is excited from the metal to the pytpy ligand, whereas the alkyl-substituted ligand does not participate in the process. The red-shift of the optical bands shown in Figure $12 \mathrm{~b}$ and observed in the experiments due to the protonation of the pyridine ring in $\mathbf{C 1 1 - H}$ is also supported by the theoretical calculations. In this latter complex, three ${ }^{1}$ MLCT states are predicted in the visible region (at 439, 653, and $717 \mathrm{~nm}$ ). The two lowest-energy states may be described via the electronic density redistribution from the iron atom to the protonated pyridine ring of the pytpy ligand. The red-shift is thus rationalized and ascribed to the electron-withdrawing effect of the additional proton, which stabilizes the electron density distributed over the $\pi^{*}$ orbital in the ${ }^{1}$ MLCT excited state.

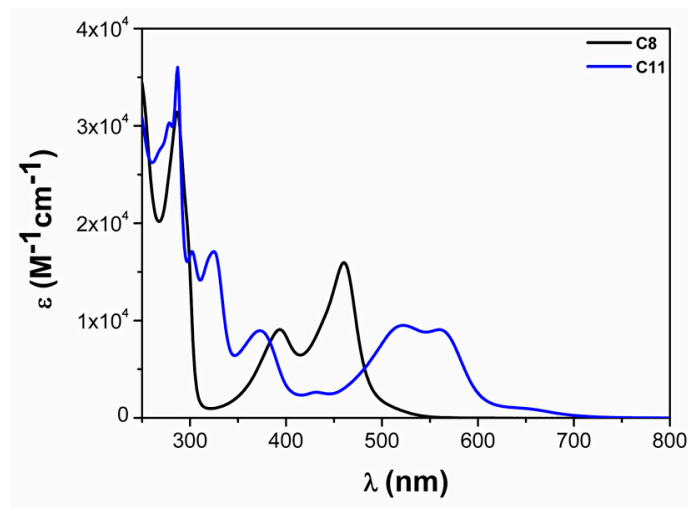

(a)

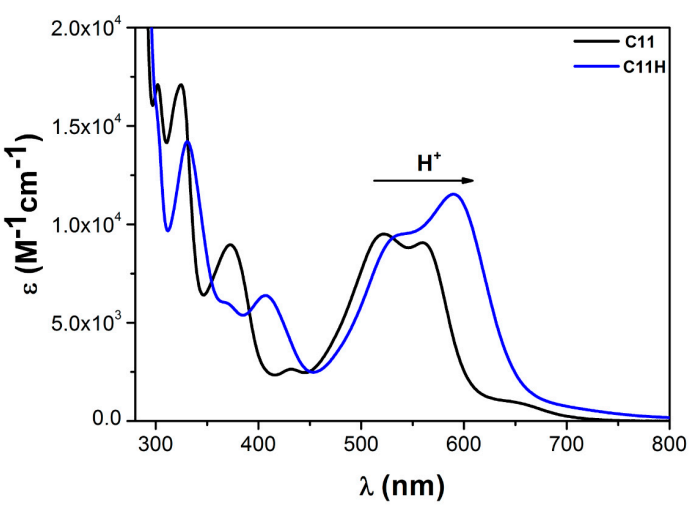

(b)

Figure 12. Comparison of absorption spectra in air-equilibrated acetonitrile solution at room temperature: (a) C8 and C11; (b) C11 and C11-H. Figure 12b reprinted with permission from Ref. [38] (Copyright @ 2014 WILEY-VCH Verlag GmbH \& Co. KGaA, Weinheim).

From the previous section, it appears that the main absorption band of C11 in the 480 to $600 \mathrm{~nm}$ range does only imply MLCT transitions to the pytpy moiety and not to the NHC ligand. Transient absorption spectroscopy reveals, however, that both transitions lead to two clearly different relaxation pathways. TAS was carried out with pump pulses at $480 \mathrm{~nm}$ for this complex, which leads to excitation of both transitions, in particular the high-energy one at $505 \mathrm{~nm}$, favoring charge transfer to the peripheral pyridine moiety (Figure 13). However, the high-energy tail of the lower energy ${ }^{1} \mathrm{MLCT}$ transition at $560 \mathrm{~nm}$ is also excited. The data (Figure 14) can be best described by two independent pathways, one of them following Equation (2), i.e., ultrafast SCO, and the other one a generalized version of Equation (1), avoiding SCO. Indeed, the sub-100 fs spectra are very similar to those of C10, with the ultrafast decay of the ESA in the $400-470 \mathrm{~nm}$ range, indicating MLCT decay and a sharpening of the $340 \mathrm{~nm}$ ESA for time delays $<0.2 \mathrm{ps}$, attributed to the population of the ${ }^{5} \mathrm{~T}_{2}$ state. Interestingly, the inset in Figure 14b shows an overdamped wave packet oscillation with a 330-fs period, probed at the ${ }^{5} \mathrm{~T}_{2}$ ESA wavelength. A similar relaxation-induced vibrational wave packet was reported for $\mathrm{Fe}(\mathrm{bpy})_{3}$ [24], but with a shorter period, which is consistent with the smaller ligands in these complexes. 


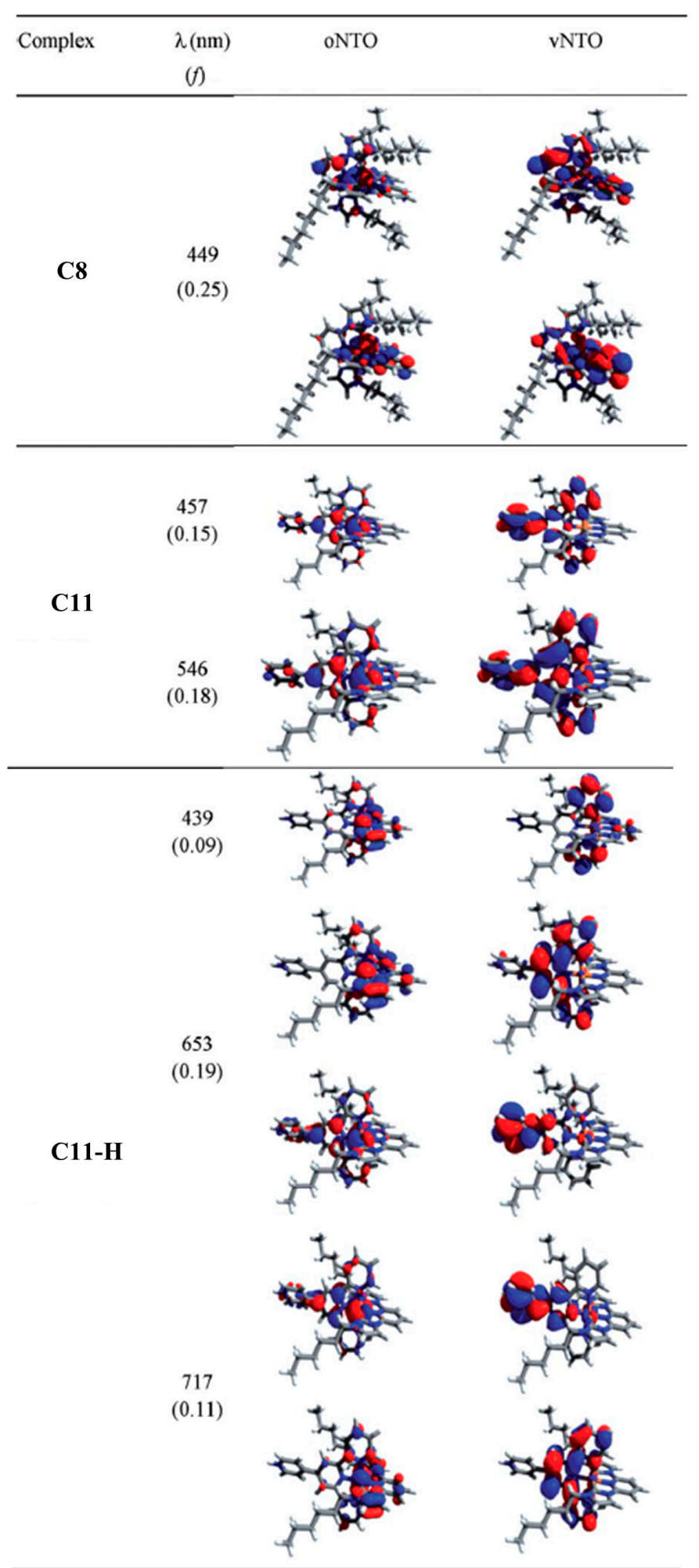

Figure 13. NTO isodensity surface of $\mathbf{C 8}, \mathbf{C 1 1}$, and $\mathbf{C 1 1}-\mathbf{H}$ species describing the ${ }^{1}$ MLCT states at the Franck-Condon region. $\lambda$ is the absorption wavelength, $f$ stands for oscillator strength, and oNTO and vNTO stand for "occupied" and "virtual" NTO, respectively. Reprinted with permission from Ref. [38] (Copyright @ 2014 WILEY-VCH Verlag GmbH \& Co. KGaA, Weinheim, Germany). 




(a)

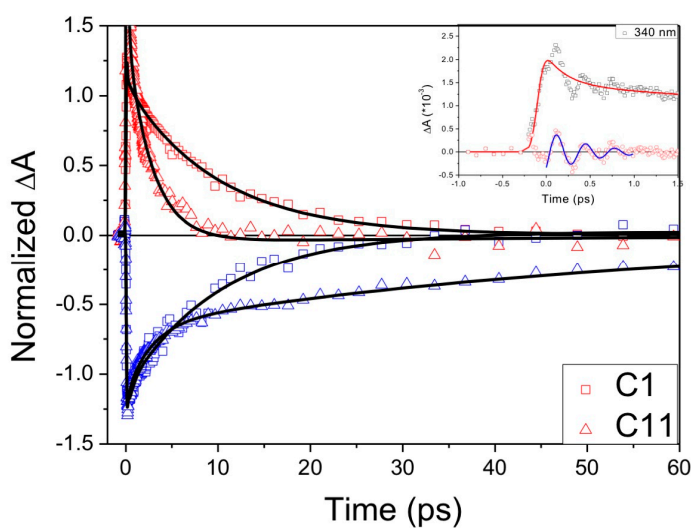

(b)

Figure 14. Femtosecond transient absorption spectroscopy (TAS) of C11 in acetonitrile at neutral $\mathrm{pH}$. (a) Time-resolved $\triangle \mathrm{A}$ spectra highlighting the occurrence of the ${ }^{5} \mathrm{~T}_{2}$ ESA at $340 \mathrm{~nm}$. Data in the 460-510 nm region were replaced by a straight line. (b) Kinetic traces of ESA (red) and GSB (blue) of $\mathbf{C 1 1}$ compared to $\mathbf{C}$. The ESA probed at $650 \mathrm{~nm}$ reflects the $2.7 \mathrm{ps}$ decay, clearly shorter than the ${ }^{3}$ MLCT decay in C1. For C11, GSB recovery at $375 \mathrm{~nm}$ is double-exponential with 2.7 and 55 ps decay times. Inset: Kinetic trace at $340 \mathrm{~nm}$ highlighting overdamped oscillations with a $330 \mathrm{fs}$ period.

Unlike C10, however, an additional 2.7 ps decay time is observed both in the ESA spectra $>600 \mathrm{~nm}$ and in the GSB recovery at all bleach wavelengths (Figure 14b). It is absent in the ${ }^{5} \mathrm{~T}_{2}$ ESA at $340 \mathrm{~nm}$, stressing the interpretation of two independent relaxation pathways, with the second one accessed from the 505-nm excitation not leading to SCO. Notably, both transitions at 505 and $560 \mathrm{~nm}$ share the same $t_{2 \mathrm{~g}}$ ground state, since the GSB spectrum in the $470-600 \mathrm{~nm}$ range is identical to the ground-state absorption (Figure 12a), so that both the 2.7 ps and the slow 55 ps decay of ${ }^{5} \mathrm{~T}_{2}$ are found in the GSB recovery. The electronic nature associated with the 2.7 ps lifetime state is not clear. Excitation at $580 \mathrm{~nm}$ reduces its amplitude slightly relative to the GSB, indicating that it is related to the excited state reached by the $505 \mathrm{~nm}$ transition. In addition to the $>600 \mathrm{~nm}$ ESA, it has also some ESA in the $400-470 \mathrm{~nm}$ range, since the GSB is almost canceled. While ${ }^{5} \mathrm{~T}_{2}$ does not have long-wavelength ESA [28], it has recently been shown, for $\left[\mathrm{Fe}(\mathrm{bpy})(\mathrm{CN})_{4}\right]_{2}$ in different solvents, that both ${ }^{3} \mathrm{MC}$ and ${ }^{3} \mathrm{MLCT}$ states show this kind of feature [32]. In any case, the effect of the additional pyridine is interesting in that it leads to an SCO-avoiding pathway. The latter, however, is not very useful for light-harvesting, since irrespective of the nature of the excited state, 2.7 ps is probably too short a lifetime.

In summary, the introduction of the pytpy ligand is beneficial for extending the absorption bandwidth, but the presence of the NHC counterpart is not sufficient to avoid SCO. An interesting coexistence of two independent pathways is found: involving either ultrafast SCO or non-SCO MLCT decay.

The preceding section has shown that a concerted combination of TD-DFT modeling and ultrafast spectroscopy is able to identify excitation wavelength-dependent relaxation pathways. Interestingly, C11 is an example where SCO-producing and avoiding-excited-state pathways coexist, depending on the localization of the charge promoted by the selected MLCT transition. While femtosecond transient absorption spectroscopy excels in time resolution, it remains a challenge to differentiate ${ }^{3}$ MLCT and ${ }^{3} \mathrm{MC}$ states from the structure of the TAS spectra.

\section{Photovoltaic Properties of Iron-NHC Complexes}

\subsection{Homoleptic Complexes}

To evaluate the photovoltaic performances of these promising new iron-NHC complexes, DSSC cells were assembled using these compounds as the sensitizers. At a first stage, the photovoltaic 
properties for the homoleptic complexes $\mathbf{C} 2$ and $\mathbf{C} 4$ were investigated, since they both bear carboxylic functionalities acting as grafting groups for the $\mathrm{TiO}_{2}$ substrate [30,35].

In Figure 15a, the Incident-Photon-to-Current-Efficiency (IPCE) plots of $\mathbf{C} 2$ and $\mathbf{C} 4$ are collected. As it can be observed, the former led to a modest, though appreciable, IPCE value (about $2.3 \%$ at $500 \mathrm{~nm}$ ). As for C4, however, only negligible electron injection was detected. In any case, it is important to bear in mind that even if modest for practical applications, those results represent the first evidence of a photocurrent generated using iron-NHC complexes. Concerning the measured photocurrent densities, DSSC cells sensitized with $\mathbf{C} 2$ exhibited values three times higher than those with $\mathbf{C} 4\left(0.41 \mathrm{vs} .0 .12 \mathrm{~mA} \mathrm{~cm}{ }^{-2}\right)$, along with a $20 \%$ increment in open circuit voltage $\left(\mathrm{V}_{\mathrm{oc}}\right.$. Despite their good optical and photophysical properties, both the poor performance of the $\mathrm{C} 4$ complex and the extremely low photocurrents measured for $\mathbf{C} 2$ point to a nonoptimal interfacial charge separation process, possibly associated with a fast recombination mechanism occurring in the pico- and nanosecond timescale. These suggestions suppose that the relatively high injection yield reported by Wärnmark [26] for $\mathbf{C 2}$ grafted on $\mathrm{TiO}_{2}$ is valid in our systems. Indeed, and as compared to the typical $50 \mathrm{ps}$ time window required for complete charge injection of the Ru N719 dye [39], the excited-state lifetimes of C2 and C4 in acetonitrile (16 and 26 ps, respectively), should afford a PCE (Photon Conversion Efficiency) $>1 \%$. In addition, as shown in Table 2, the surface dye load value for $\mathbf{C} 2$ is even larger than that of the N719 reference dye, which shows state-of-the-art PCE properties, allowing us to leave out any problems related to an ineffective $\mathrm{TiO}_{2}$ sensitization. Strikingly, the IPCE spectrum of $\mathbf{C} 4$ does not show any sensitization activity of the MLCT transitions of this complex (Figure 15a).

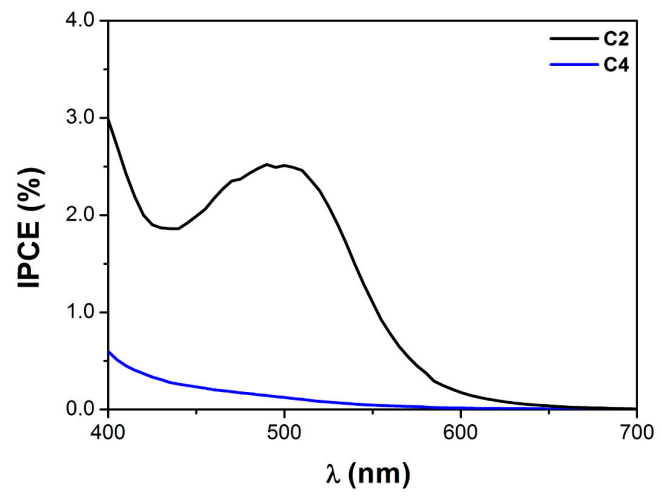

(a)

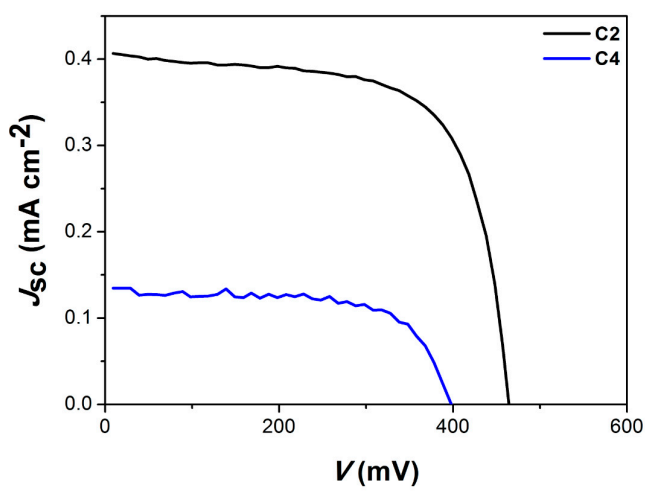

(b)

Figure 15. (a) Incident-Photon-to-Current-Efficiency (IPCE) curves for DSSCs sensitized with C2 (black) and $\mathrm{C} 4$ (red line) using $\mathrm{I}_{2} / \mathrm{I}^{-}$as the mediator. (b) $J-V$ curve and performance data of DSSCs sensitized with C2 and C4. Reproduced from Ref. [35] with permission from the PCCP Owner Societies.

Table 2. Photovoltaic performance of DSSCs based on C2, C4, and N719 a .

\begin{tabular}{cccccc}
\hline Dye & $J_{S_{c}}\left(\mathbf{m A} / \mathbf{c m}^{\mathbf{2}}\right)$ & $\mathbf{V}_{\text {oc }}(\mathbf{m V})$ & $\boldsymbol{F F}$ & $\boldsymbol{P C E} \%$ & Dye Load $\left(\mu \mathrm{mol} / \mathrm{cm}^{2}\right)^{\mathbf{b}}$ \\
\hline $\mathrm{C} 2$ & 0.41 & 457 & 0.68 & 0.13 & 0.09 \\
$\mathrm{C} 4$ & 0.12 & 368 & 0.71 & 0.03 & 0.06 \\
$\mathbf{N 7 1 9}$ & 13.25 & 687 & 0.67 & 6.1 & 0.08 \\
TiO $_{2}$ & 0.01 & 364 & 0.51 & 0.01 & -
\end{tabular}

${ }^{\text {a }}$ Measurements performed under AM $1.5 \mathrm{G}$ irradiation $\left(100 \mathrm{~mW} \cdot \mathrm{cm}^{-2}\right)$; irradiated area: $0.36 \mathrm{~cm}^{2}$ on $\mathrm{TiO}_{2}$ layers $(10-11 \mu \mathrm{m})$. Values obtained from at least three DSSCs for each dye. ${ }^{b}$ Dye load calculated from absorbance data of the sensitized electrode. Values confirmed by desorption of dyes from $\mathrm{TiO}_{2}$ under basic conditions. $J_{\mathrm{sc}}$ : short-circuit photocurrent, FF: Fill Factor.

To gain insight into the peculiar interfacial properties of the $\mathbf{C 2}$ - and $\mathbf{C} 4$-sensitized $\mathrm{TiO}_{2}$ interfaces and hence provide a fundamental understanding of the charge generation and sensitization capabilities, 
we reported a quantitative analysis based on high-level DFT calculations and the modelling of the relevant interfacial electron-transfer processes [35].

The electronic structure of the $\mathbf{C} 2$ - and $\mathbf{C} 4$-sensitized $\mathrm{TiO}_{2}$ interfaces can be analyzed by looking at the projected density of states (PDOS) and frontier molecular orbitals (MOs) (Figure 16), obtained by DFT calculations in an implicit acetonitrile solution with the hybrid B3LYP functional and a 6-31G* basis set. More details on the methodology adopted and the calculations performed can be found in Ref. [35]. The $\mathrm{Fe}(\mathrm{II})$-carbene $/ \mathrm{TiO}_{2}$ interfaces show the typical alignment of $\mathrm{Ru}(\mathrm{II})-$ polypyridyl $/ \mathrm{TiO}_{2}$ interfaces, with the HOMOs and LUMOs lying above the semiconductor valence band (VB) and conduction band (CB), respectively $[40,41]$. Both dyes present HOMOs completely delocalized and significantly mixed with the $\mathrm{TiO}_{2} \mathrm{VB}$ states (around 30-50\%), as can be inferred by the tail of the $\mathrm{TiO}_{2}$ VB PDOS extending through the dye's HOMOs PDOS. This might suggest a facile back electron recombination between the injected electrons and the oxidized chromophore. However, a closer look at the nature and alignment of the unoccupied states discloses more detailed information on the interfacial charge separation and electron injection efficiency. For both $\mathbf{C} 2$ and $\mathbf{C 4}$, the dye's LUMO, lying at -2.63 and $-2.71 \mathrm{eV}$, respectively, appears to be uncoupled with the $\mathrm{TiO}_{2} \mathrm{CB}$ states $(93 \%$ and $97 \%$ of electron density localization on the dye for $\mathbf{C} 2$ and $\mathbf{C} 4$, respectively), and more importantly, it is localized over the ligand, not anchored to the $\mathrm{TiO}_{2}$ surface (see isodensity plots in Figure 16). Contrarily, the LUMO+1 distribution is markedly broadened and strongly coupled with the CB states. The lower-energy tail of the LUMO+1 shows contributions mainly localized on the grafted moiety with strong delocalization toward the $\mathrm{CB} \mathrm{TiO}_{2}$ states, while at higher energies, significant contributions on the non-anchored ligand still appear, particularly for $\mathbf{C} 2$. These results clearly indicate that even if the interfacial energy level alignment is favorable for an efficient electron injection step, the primary charge transfer associated to the lowest-energy MLCT state goes in the opposite direction with respect to the injection into the $\mathrm{TiO}_{2} \mathrm{CB}$. This aspect directly comes from the bidentate adsorption of the deprotonated dye onto the semiconductor surface, which removes the near degeneracy between the two lowest unoccupied orbitals localized on the two ligands. As the $\mathrm{TiO}_{2}$ electron-accepting capability is weaker than that of the opposite proton, the orbitals localized on the anchored ligand are destabilized with respect to the one bearing the free $\mathrm{COOH}$ group. It is important to point out, however, that the cell preparation and operational conditions might sizeably change the extent of the energy splitting between these two MLCT states. In particular, ionic additives in the electrolyte, acidic treatment of $\mathrm{TiO}_{2}, \mathrm{pH}$, and the coexistence of different anchoring modes can restore/remove their near degeneracy. In fact, as discussed in Ref. [35], the deprotonation of the not-coordinated $\mathrm{COOH}$ group in $\mathbf{C 2}$ is sufficient to revert the LUMO/LUMO+1 topology and hence obtain again the correct charge flow toward the semiconductor.

\subsection{Heteroleptic Complexes}

As previously discussed on the basis of the dye $/ \mathrm{TiO}_{2}$ calculations, the presence of two carboxylic groups pointing towards opposite directions on the dye was deleterious for the injection process. Consequently, one of the carboxylic groups was removed and the heteroleptic complexes C5, C6, and C7 were investigated [35]. The complexes were prepared according to Scheme 7. Apart from the presence of only one anchoring group, different donor groups, e.g., $p$-methoxyphenyl in C6 and $p$-(diphenylamino)phenyl in C7, were introduced at the imidazole moiety. The resulting donor-acceptor $(\mathrm{COOH})$ molecular design would eventually (i) improve the vectorial electronic charge transfer into the SC and (ii) limit the possible recombination reactions by keeping the photogenerated hole far from the SC surface. 

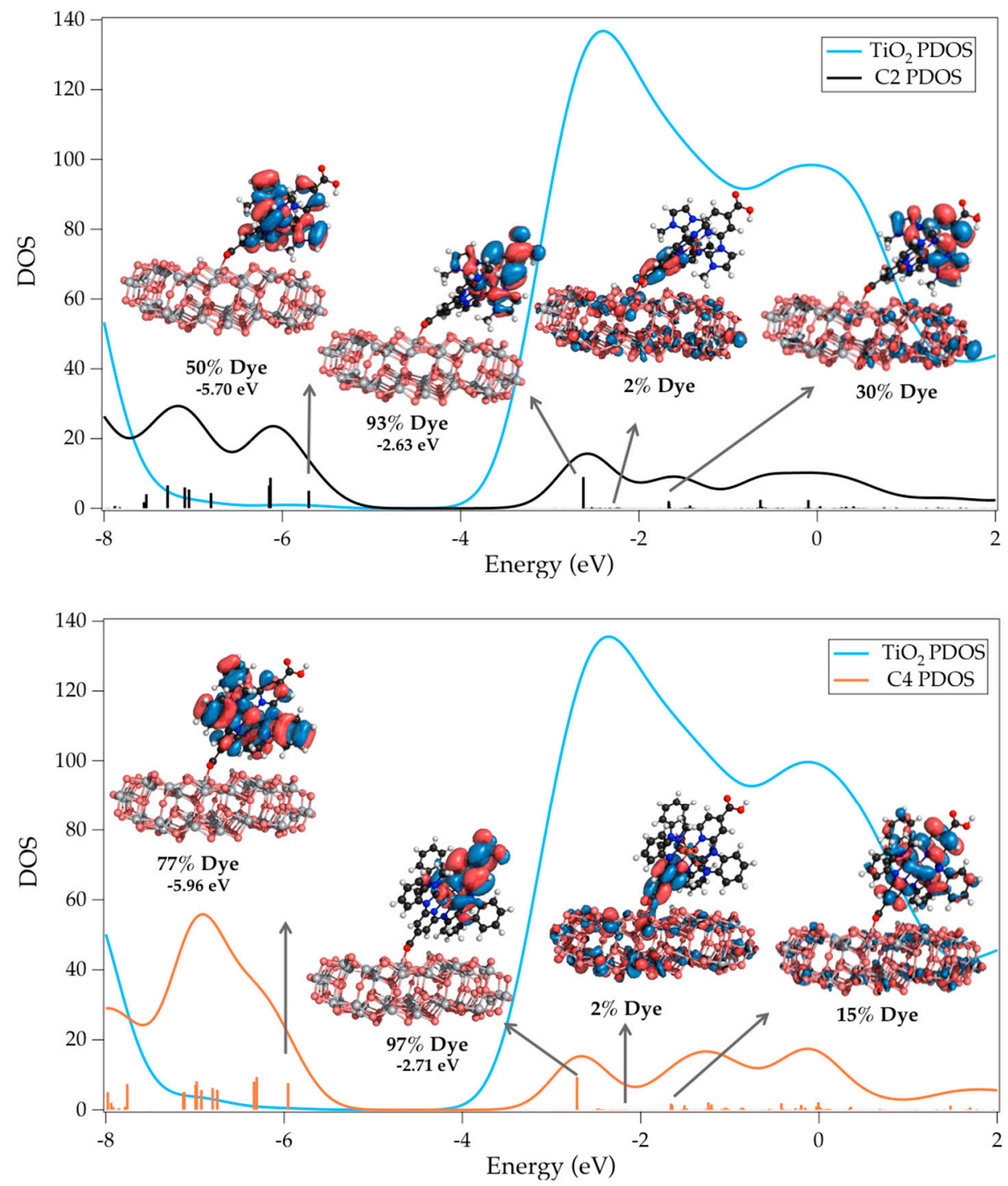

Figure 16. Projected DOS (PDOS) and the main dye's MO isodensity plots for the C2 (top) and C4 (bottom) complexes adsorbed onto the $\left(\mathrm{TiO}_{2}\right)_{82}$ cluster. For the depicted MOs, the percent contribution of the population localized on the dye is also indicated. The Gaussian broadening used to reproduce the PDOS is equal to $0.3 \mathrm{eV}$. Vertical sticks represent the Kohn-Sham eigenvalues and their intensity the percentage of the dye's population. Reproduced from Ref. [35] with permission from the PCCP Owner Societies.

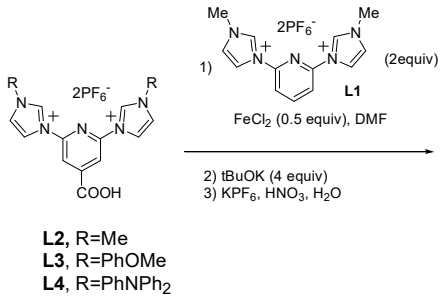

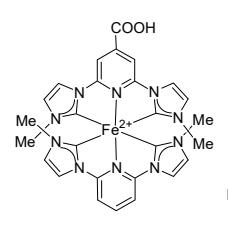

C5

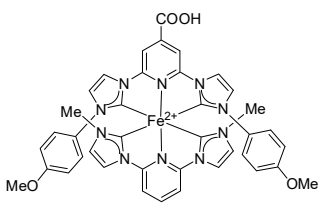

C6

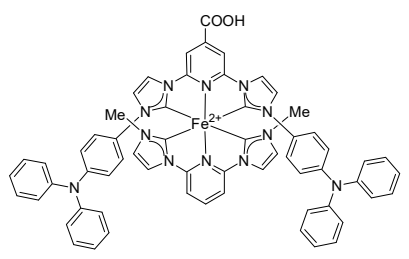

C7

Scheme 7. Synthesis of heteroleptic complexes C5, C6, and C7.

Femtosecond transient spectroscopy reveals that these four-carbene-containing complexes follow the relaxation scenario (1), as already discussed above for $\mathbf{C} 5$. They have very similar ${ }^{3}$ MLCT lifetimes 
(10 ps for $\mathbf{C 6}$ and 12 ps for C7), not above 20 ps, but still enough to expect PCE values $>1 \%$, assuming that electron injection occurs on the same timescales as for N719 [39].

The IPCE and $J-V$ curves are presented in Figure 17.

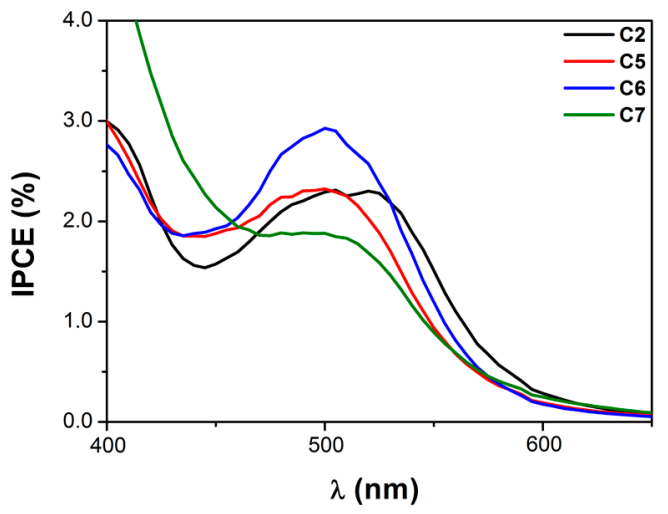

(a)

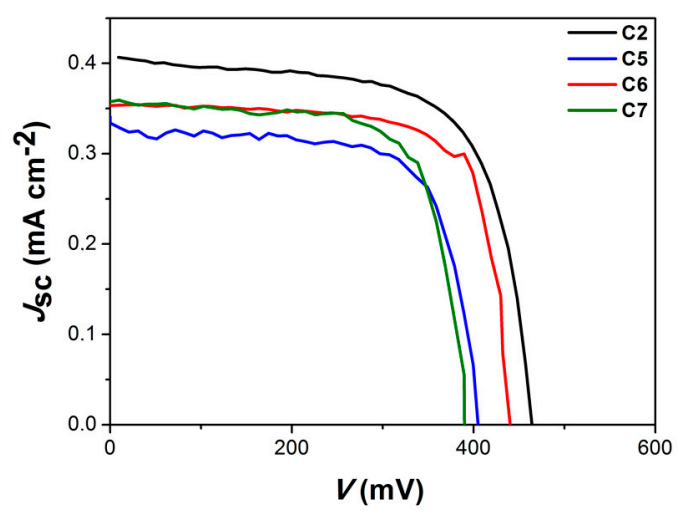

(b)

Figure 17. (a) IPCE curves and (b) J/V curves for DSSC sensitized with C2, C5, C6, and C7 using $\mathrm{I}_{2} / \mathrm{I}^{-}$as the mediator. Reproduced from Ref. [35] with permission from the PCCP Owner Societies.

From the $J-V$ curves (Figure $17 \mathrm{~b}$ ) and PV data in Table 3, despite possessing the desired interfacial charge separation properties, the photovoltaic performances of the DSSCs based on heteroleptic complexes did not overperform those from C2-sensitized ones (Table 3).

Table 3. Photovoltaic performances of DSSCs sensitized with heteroleptic dyes ${ }^{\text {a }}$.

\begin{tabular}{cccccc}
\hline Dye & $J_{\text {SC }}\left(\mathbf{m A} \cdot \mathbf{c m}^{-2}\right)$ & $V_{\text {OC }}(\mathbf{m V})$ & FF & PCE\% & Dye Load $\left(\mu \mathrm{mol} / \mathbf{c m}^{-2}\right)^{\mathbf{b}}$ \\
\hline C2 & 0.41 & 457 & 0.68 & 0.13 & 0.09 \\
C5 & 0.33 & 400 & 0.73 & 0.10 & 0.10 \\
C6 & 0.36 & 440 & 0.73 & 0.11 & 0.12 \\
C7 & 0.36 & 390 & 0.71 & 0.10 & 0.07 \\
N719 & 13.25 & 687 & 0.67 & 6.1 & 0.08 \\
\hline
\end{tabular}

a Measurements performed under AM $1.5 \mathrm{G}$ irradiation $\left(100 \mathrm{~mW} \cdot \mathrm{cm}^{-2}\right)$; irradiated area: $0.36 \mathrm{~cm}^{2}$ on $\mathrm{TiO}_{2}$ layers $(10-11 \mu \mathrm{m})$. Values obtained from at least three DSSCs per dye. ${ }^{\mathrm{b}}$ Dye load calculated from absorbance data of the sensitized electrode. Values confirmed by desorption of dyes from $\mathrm{TiO}_{2}$ under basic conditions.

Also, in this case, it can be worthwhile to examine the PDOS of the dye/ $\mathrm{TiO}_{2}$ system displayed in Figure 18. As is apparent, the desired charge-transfer nature of the lowest-energy dye level is obtained, in line with the PBE0 results reported in Ref. [42] for the same complex adsorbed on a $\left(\mathrm{TiO}_{2}\right)_{92}$ cluster model. As shown in Table 3, the PV performances, however, are still poor, and this seems to be in contradiction with the favorable energetics and topology calculated for this system.

To propose a further rationalization of the charge separation properties of the Fe(II)-NHC@ $\mathrm{TiO}_{2}$ interface, we computed the rates for both the electron transfer from the dye's donor state (LUMO or $\mathrm{LUMO}+1$, in this case) into the acceptor states of the $\mathrm{TiO} 2$ (CB) and for the back-electron transfer (recombination) from the CB states to the dye's HOMO. Table 4 reports the calculated injection probabilities, $\mathrm{G}(\varepsilon)$, obtained at the $\mathrm{LUMO} / \mathrm{LUMO}+1$ and $\mathrm{HOMO}$ energy for electron injection and recombination, respectively; the corresponding VB or CB DOS; and the injection rates, $k_{\text {inj. }}$. 


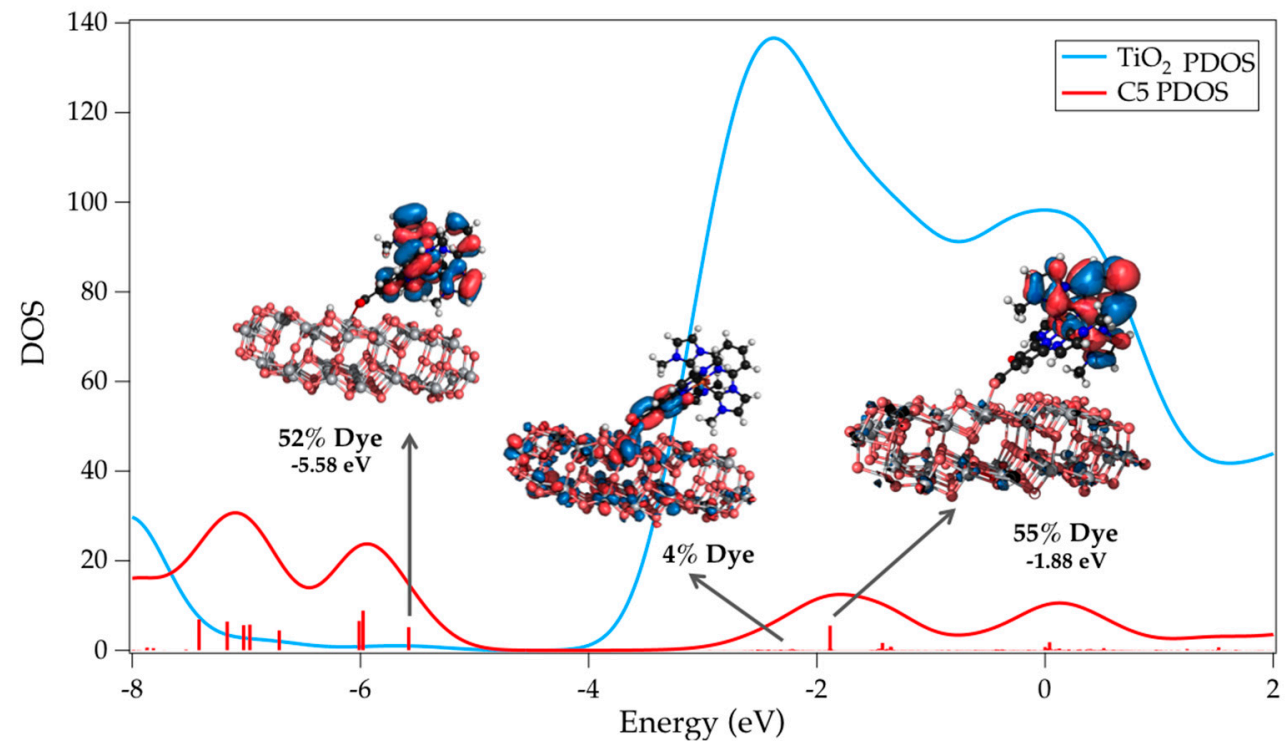

Figure 18. PDOS (Gaussian broadening $0.3 \mathrm{eV}$ ) and representative C5's $\mathrm{MO}$ isodensity plots of the $\mathrm{C} 5 @\left(\mathrm{TiO}_{2}\right)_{82}$ system. The percentage of density localization on the dye is also indicated for the plotted MOs. The vertical sticks correspond to the Khon-Sham eigenvalues and their intensity to the percentage of density localization on the dye. Reproduced from Ref. [34] with permission from the PCCP Owner Societies.

Concerning the homoleptic complexes (C2 and $\mathbf{C} 4)$, data in Table 4 indicate, as expected, that the electronic coupling between the dye's LUMO and the semiconductor's CB states is extremely weak, with $\Gamma$ values of the order of $10^{-4} \mathrm{eV}$, yielding very low injection rates of about $10^{12} \mathrm{~s}^{-1}$. That is, the electron injection for the homoleptic dyes is foreseen to occur in the ps timescale, coinciding with the timescale for the deactivation of the ${ }^{3}$ MLCT state. Moreover, a quantitative difference between C2 and C4 is also predicted, with a lower injection probability for the latter, possibly arising from the more delocalized nature of the MOs induced by the BIm groups. In line with the previous PDOS analysis (Figure 16), on the other hand, an ultrafast injection mechanism is calculated for LUMO+1, with $\Gamma$ values of the order of $10^{-1} \mathrm{eV}$ and injection rates of $10^{15} \mathrm{~s}^{-1}$ (fs timescale).

Table 4. Probability distributions, $\Gamma(\mathrm{eV})$; DOS (number of states/eV) calculated at the diabatic HOMO, LUMO, and LUMO+1 energies; and associated injection rates, $k_{\text {inj }}\left(\mathrm{s}^{-1}\right)$. Data taken from Ref. [35].

\begin{tabular}{|c|c|c|c|c|c|c|}
\hline \multicolumn{7}{|c|}{ Electron Injection } \\
\hline System & $\Gamma\left(\varepsilon_{\text {LUMO }}\right)$ & DOS $\left(\varepsilon_{\text {LUMO }}\right)$ & $k_{\text {inj }}$ & $\Gamma\left(\varepsilon_{\text {LUMO+1 }}\right)$ & DOS $\left(\varepsilon_{\text {LUMO }+1}\right)$ & $k_{\text {inj }}$ \\
\hline $\mathrm{C} 2 @ \mathrm{TiO}_{2}$ & $2.03 \times 10^{-4}$ & 129 & $1.9 \times 10^{12}$ & 0.158 & 133 & $1.5 \times 10^{15}$ \\
\hline $\mathrm{C} 4 @ \mathrm{TiO}_{2}$ & $1.67 \times 10^{-4}$ & 120 & $1.6 \times 10^{12}$ & 0.120 & 136 & $1.1 \times 10^{15}$ \\
\hline $\mathrm{C} 5 @ \mathrm{TiO}_{2}$ & 0.010 & 130 & $9.5 \times 10^{13}$ & $1.2 \times 10^{-3}$ & 120 & $1.1 \times 10^{13}$ \\
\hline \multicolumn{7}{|c|}{ Recombination to the oxidized dye } \\
\hline & \multicolumn{2}{|c|}{$\Gamma\left(\varepsilon_{\text {НОмо }}\right)$} & \multicolumn{2}{|c|}{ DOS $\left(\varepsilon_{\text {номо }}\right)$} & \multicolumn{2}{|c|}{$k_{\text {inj }}$} \\
\hline $\mathrm{C} 2 @ \mathrm{TiO}_{2}$ & \multicolumn{2}{|c|}{$1.0 \times 10^{-11}$} & \multicolumn{2}{|c|}{$1 \times 10^{-8}$} & \multicolumn{2}{|c|}{$9.5 \times 10^{4}$} \\
\hline $\mathrm{C} 4 @ \mathrm{TiO}_{2}$ & \multicolumn{2}{|c|}{$5.0 \times 10^{-10}$} & \multicolumn{2}{|c|}{$3 \times 10^{-6}$} & \multicolumn{2}{|c|}{$4.8 \times 10^{7}$} \\
\hline $\mathrm{C} 5 @ \mathrm{TiO}_{2}$ & \multicolumn{2}{|c|}{$3.0 \times 10^{-12}$} & \multicolumn{2}{|c|}{$6 \times 10^{-9}$} & \multicolumn{2}{|c|}{$2.6 \times 10^{4}$} \\
\hline
\end{tabular}

Turning now to the heteroleptic $\mathbf{C 5}$ complex, an appreciable change in the electronic structure, i.e., in the diabatic LUMO nature, is obtained, resulting in lower electronic coupling with the low-energy $\mathrm{TiO}_{2} \mathrm{CB}$ states (where the LUMO is energetically located) and larger coupling with higher-energy states (more details can be found in Ref. [35]). As a consequence, the calculated $\Gamma\left(\varepsilon_{\text {LUMO }}\right)$ for C5, 
despite the correct interfacial charge-transfer topology, is also in the range of several ps; that is, in the same timescale as the ${ }^{3} \mathrm{MLCT}$ lifetimes (14 ps).

Further understanding also comes from the hole injection analysis. Even if, as shown by the data in Table 4, in our diabatic-like scheme recombination to the oxidized dye is calculated to be extremely slow, as a consequence of the negligible energetic overlap between the dye $\mathrm{HOMO}$ and the $\mathrm{TiO}_{2} \mathrm{CB}$ states ( $\mathrm{ms}$ timescale), we found for $\mathbf{C} 2, \mathbf{C} 5$, and $\mathbf{C} 4$ (even if at a lower extent) a large electronic coupling with both the VB and $\mathrm{CB}$ states due to the above discussed high delocalization of the HOMO boosting the electronic conjugation with the $\mathrm{TiO}_{2} \mathrm{MOs}$ [35]. It is worthwhile to stress that in the complexity of the "working" dye-sensitized electrode, where heterogeneous binding and pair interactions perturb the energetics discussed so far, the actual back-recombination processes might be faster, taking place in the nanosecond and even picosecond timescale, as reported in Ref. [26].

\section{Conclusions and Outlook}

In this review, we have shown the impact of different molecular designs of iron(II) complexes on their photophysical and electrochemical properties. In particular, the key strategies to enlarge their light absorption range as well as to increase their excited-state lifetimes are presented. Thus, upon a judicious chemical design to adequately tune their optoelectronic properties, NHC-based iron(II) complexes can be regarded as promising sensitizers for DSSCs, which truly turns them into valuable alternatives to rare metals such as ruthenium.

In iron(II) complexes, the sufficient destabilization of low-lying MC states in order to allow the exploitation of MLCT states, such as for electron injection into the SC band, is highly challenging. In this regard, NHC coordinating units are of fundamental importance. By modifying the ligands around the iron center as stated, we succeeded in improving the excited-state lifetime by up to $26 \mathrm{ps,}$ especially using the benzimidazolylidene moiety as the carbenic part. It is worth noting that TD-DFT computations revealed for the first time a ${ }^{3} \mathrm{MLCT} /{ }^{3} \mathrm{MC}$-level inversion.

The good absorption features and the remarkably long-lived MLCT excited states encouraged their use as dyes for DSSC. The first DSSC units assembled with a set of NHC-based iron complexes show that (i) they can effectively sensitize titanium dioxide and (ii) their MLCT band can be excited to produce a photocurrent upon solar irradiation. However, despite a priori sufficiently long MLCT lifetimes, the efficiency of the cells was found to be low.

By means of interfacial DFT calculations, we demonstrate the presence of inefficient electron coupling between the sensitizers and the SC orbitals, thus considerably decreasing the injection rate that falls in the same regime as the MLCT/MC deactivation process.

Work is in progress to design new complexes combining further-improved excited-state lifetimes and absorbances, along with appropriate electronic properties for better cell performances. Here, in addition to tuning of the ground-state properties (ligand field splitting), design strategies that influence the nonadiabatic excited-state relaxation kinetics [27] remain unexplored for the moment.

From a spectroscopic point of view, additional methods are needed to determine the location of the electronic states along the excited-state relaxation pathway. We recently showed, by ultrafast fluorescence spectroscopy, that the ${ }^{3} \mathrm{MLCT}$ in Fe(II)-NHC complexes has a relatively small red-shift of $(<0.4 \mathrm{eV})$ with respect to ${ }^{1}$ MLCT [43]. Besides, it is highly desirable to reveal metal-centered $\mathrm{d}-\mathrm{d}$ transitions and thus to obtain direct evidence for the impact of chemical design on the induced ligand field splitting.

Author Contributions: All the authors contributed equally to the writing of this review according to their field of expertise.

Funding: The project is funded by the French Agence Nationale de Recherche under the PhotoIron project (ANR-16-CE07-0013-02).

Conflicts of Interest: The authors declare no conflict of interest. 


\section{References}

1. Jung, H.S.; Lee, J.-K. Dye Sensitized Solar Cells for Economically Viable Photovoltaic Systems. J. Phys. Chem. Lett. 2013, 4, 1682-1693. [CrossRef] [PubMed]

2. Hagfeldt, A.; Boschloo, G.; Sun, L.; Kloo, L.; Pettersson, H. Dye-Sensitized Solar Cells. Chem. Rev. 2010, 110, 6595-6663. [CrossRef] [PubMed]

3. Hardin, B.E.; Hoke, E.T.; Armstrong, P.B.; Yum, J.-H.; Comte, P.; Torres, T.; Fréchet, J.M.J.; Nazeeruddin, M.K.; Grätzel, M.; McGehee, M.D. Increased Light Harvesting in Dye-Sensitized Solar Cells with Energy Relay Dyes. Nat. Photonics 2009, 3, 406-411. [CrossRef]

4. Sauvage, J.P.; Collin, J.P.; Chambron, J.C.; Guillerez, S.; Coudret, C.; Balzani, V.; Barigelletti, F.; De Cola, L.; Flamigni, L. Ruthenium(II) and Osmium(II) Bis(Terpyridine) Complexes in Covalently-Linked Multicomponent Systems: Synthesis, Electrochemical Behavior, Absorption Spectra, and Photochemical and Photophysical Properties. Chem. Rev. 1994, 94, 993-1019. [CrossRef]

5. Dixon, I.M.; Lebon, E.; Sutra, P.; Igau, A. Luminescent Ruthenium-Polypyridine Complexes \& Phosphorus Ligands: Anything but a Simple Story. Chem. Soc. Rev. 2009, 38, 1621. [PubMed]

6. Beley, M.; Gros, P.C. Ruthenium Polypyridine Complexes Bearing Pyrroles and $\pi$-Extended Analogues. Synthesis, Spectroelectronic, Electrochemical, and Photovoltaic Properties. Organometallics 2014, 33, 4590-4606. [CrossRef]

7. Nazeeruddin, M.K.; De Angelis, F.; Fantacci, S.; Selloni, A.; Viscardi, G.; Liska, P.; Ito, S.; Takeru, B.; Grätzel, M. Combined Experimental and DFT-TDDFT Computational Study of Photoelectrochemical Cell Ruthenium Sensitizers. J. Am. Chem. Soc. 2005, 127, 16835-16847. [CrossRef] [PubMed]

8. Fantacci, S.; De Angelis, F.; Selloni, A. Absorption Spectrum and Solvatochromism of the $\left[\mathrm{Ru}\left(4,4^{\prime}-\right.\right.$ $\left.\mathrm{COOH}-2,2^{\prime}-\mathrm{Bpy}\right)_{2}(\mathrm{NCS})_{2}$ ] Molecular Dye by Time Dependent Density Functional Theory. J. Am. Chem. Soc. 2003, 125, 4381-4387. [CrossRef] [PubMed]

9. Hagfeldt, A.; Peter, L. Dye-Sensitized Solar Cells; Kalyanasundaram, K., Ed.; EPFL Press: Lausanne, Switzerland, 2010.

10. Listorti, A.; Creager, C.; Sommeling, P.; Kroon, J.; Palomares, E.; Fornelli, A.; Breen, B.; Barnes, P.R.F.; Durrant, J.R.; Law, C.; et al. The Mechanism behind the Beneficial Effect of Light Soaking on Injection Efficiency and Photocurrent in Dye Sensitized Solar Cells. Energy Environ. Sci. 2011, 4, 3494-3501. [CrossRef]

11. Listorti, A.; O’Regan, B.; Durrant, J.R. Electron Transfer Dynamics in Dye-Sensitized Solar Cells. Chem. Mater. 2011, 23, 3381-3399. [CrossRef]

12. Lobello, M.G.; Fantacci, S.; De Angelis, F. Computational Spectroscopy Characterization of the Species Involved in Dye Oxidation and Regeneration Processes in Dye-Sensitized Solar Cells. J. Phys. Chem. C 2011, 115, 18863-18872. [CrossRef]

13. McCusker, J.K.; Walda, K.N.; Dunn, R.C.; Simon, J.D.; Magde, D.; Hendrickson, D.N. Subpicosecond 1MLCT. Fwdarw. 5T2 Intersystem Crossing of Low-Spin Polypyridyl Ferrous Complexes. J. Am. Chem. Soc. 1993, 115, 298-307. [CrossRef]

14. Ferrere, S.; Gregg, B.A. Photosensitization of $\mathrm{TiO}_{2}$ by $\left[\mathrm{Fe}^{\mathrm{II}}\left(2,2^{\prime} \text {-Bipyridine-4, } 4^{\prime} \text {-Dicarboxylic Acid }\right)_{2}(\mathrm{CN})_{2}\right]$ : Band Selective Electron Injection from Ultra-Short-Lived Excited States. J. Am. Chem. Soc. 1998, 120, 843-844. [CrossRef]

15. Ferrere, S. New Photosensitizers Based upon $\left[\mathrm{Fe}(\mathrm{L})_{2}(\mathrm{CN})_{2}\right]$ and $\left[\mathrm{Fe}(\mathrm{L})_{3}\right](\mathrm{L}=$ Substituted 2,2'-Bipyridine): Yields for the Photosensitization of $\mathrm{TiO}_{2}$ and Effects on the Band Selectivity. Chem. Mater. 2000, 12, 1083-1089. [CrossRef]

16. Dixon, I.M.; Khan, S.; Alary, F.; Boggio-Pasqua, M.; Heully, J.-L. Probing the Photophysical Capability of Mono and Bis(Cyclometallated) Fe(II) Polypyridine Complexes Using Inexpensive Ground State DFT. Dalton Trans. 2014, 43, 15898-15905. [CrossRef] [PubMed]

17. Housecroft, C.E.; Constable, E.C. The Emergence of Copper(I)-Based Dye Sensitized Solar Cells. Chem. Soc. Rev. 2015, 44, 8386-8398. [CrossRef] [PubMed]

18. Sandroni, M.; Kayanuma, M.; Planchat, A.; Szuwarski, N.; Blart, E.; Pellegrin, Y.; Daniel, C.; Boujtita, M.; Odobel, F. First Application of the HETPHEN Concept to New Heteroleptic Bis(Diimine) Copper(i) Complexes as Sensitizers in Dye Sensitized Solar Cells. Dalton Trans. 2013, 42, 10818. [CrossRef] [PubMed]

19. Monat, J.E.; McCusker, J.K. Femtosecond Excited-State Dynamics of an Iron(II) Polypyridyl Solar Cell Sensitizer Model. J. Am. Chem. Soc. 2000, 122, 4092-4097. [CrossRef] 
20. Zhang, W.; Alonso-Mori, R.; Bergmann, U.; Bressler, C.; Chollet, M.; Galler, A.; Gawelda, W.; Hadt, R.G.; Hartsock, R.W.; Kroll, T.; et al. Tracking Excited-State Charge and Spin Dynamics in Iron Coordination Complexes. Nature 2014, 509, 345-348. [CrossRef] [PubMed]

21. Jakubikova, E.; Bowman, D.N. Fe(II)-Polypyridines as Chromophores in Dye-Sensitized Solar Cells: A Computational Perspective. Acc. Chem. Res. 2015, 48, 1441-1449. [CrossRef] [PubMed]

22. Auböck, G.; Chergui, M. Sub-50-Fs Photoinduced Spin Crossover in $\left[\mathrm{Fe}(\mathrm{Bpy})_{3}\right]^{2+}$. Nat. Chem. 2015, 7, 629-633. [CrossRef] [PubMed]

23. Meyer, T.J. Photochemistry of Metal Coordination Complexes: Metal to Ligand Charge Transfer Excited States. Pure Appl. Chem. 1986, 58, 1193-1206. [CrossRef]

24. Consani, C.; Prémont-Schwarz, M.; ElNahhas, A.; Bressler, C.; van Mourik, F.; Cannizzo, A.; Chergui, M. Vibrational Coherences and Relaxation in the High-Spin State of Aqueous $\left[\mathrm{Fe}^{\mathrm{II}}(\mathrm{Bpy})_{3}\right]^{2+}$. Angew. Chem. Int. Ed. 2009, 48, 7184-7187. [CrossRef] [PubMed]

25. Liu, Y.; Harlang, T.; Canton, S.E.; Chábera, P.; Suárez-Alcántara, K.; Fleckhaus, A.; Vithanage, D.A.; Göransson, E.; Corani, A.; Lomoth, R.; et al. Towards Longer-Lived Metal-to-Ligand Charge Transfer States of Iron(II) Complexes: An N-Heterocyclic Carbene Approach. Chem. Commun. 2013, 49, 6412. [CrossRef] [PubMed]

26. Harlang, T.C.B.; Liu, Y.; Gordivska, O.; Fredin, L.A.; Ponseca, C.S.; Huang, P.; Chábera, P.; Kjaer, K.S.; Mateos, H.; Uhlig, J.; et al. Iron Sensitizer Converts Light to Electrons with 92\% Yield. Nat. Chem. 2015, 7, 883-889. [CrossRef] [PubMed]

27. Fredin, L.A.; Pápai, M.; Rozsályi, E.; Vankó, G.; Wärnmark, K.; Sundström, V.; Persson, P. Exceptional Excited-State Lifetime of an Iron(II)-N-Heterocyclic Carbene Complex Explained. J. Phys. Chem. Lett. 2014, 5, $2066-2071$. [CrossRef] [PubMed]

28. Liu, Y.; Persson, P.; Sundström, V.; Wärnmark, K. Fe N -Heterocyclic Carbene Complexes as Promising Photosensitizers. Acc. Chem. Res. 2016, 49, 1477-1485. [CrossRef] [PubMed]

29. Shepard, S.G.; Fatur, S.M.; Rappé, A.K.; Damrauer, N.H. Highly Strained Iron(II) Polypyridines: Exploiting the Quintet Manifold to Extend the Lifetime of MLCT Excited States. J. Am. Chem. Soc. 2016, 138, 2949-2952. [CrossRef] [PubMed]

30. Duchanois, T.; Etienne, T.; Cebrián, C.; Liu, L.; Monari, A.; Beley, M.; Assfeld, X.; Haacke, S.; Gros, P.C. An Iron-Based Photosensitizer with Extended Excited-State Lifetime: Photophysical and Photovoltaic Properties: An Iron-Based Photosensitizer with Extended Excited-State Lifetime. Eur. J. Inorg. Chem. 2015, 2015, 2469-2477. [CrossRef]

31. Liu, Y.; Kjaer, K.S.; Fredin, L.A.; Chábera, P.; Harlang, T.; Canton, S.E.; Lidin, S.; Zhang, J.; Lomoth, R.; Bergquist, K.-E.; et al. A Heteroleptic Ferrous Complex with Mesoionic Bis(1,2,3-Triazol-5-Ylidene) Ligands: Taming the MLCT Excited State of Iron(II). Chem. Eur. J. 2015, 21, 3628-3639. [CrossRef] [PubMed]

32. Kjær, K.S.; Zhang, W.; Alonso-Mori, R.; Bergmann, U.; Chollet, M.; Hadt, R.G.; Hartsock, R.W.; Harlang, T.; Kroll, T.; Kubiček, K.; et al. Ligand Manipulation of Charge Transfer Excited State Relaxation and Spin Crossover in [Fe(2,2'-Bipyridine $)_{2}(\mathrm{CN})_{2}$ ]. Struct. Dyn. 2017, 4, 044030. [CrossRef] [PubMed]

33. Kjær, K.S.; Kunnus, K.; Harlang, T.C.B.; Van Driel, T.B.; Ledbetter, K.; Hartsock, R.W.; Reinhard, M.E.; Koroidov, S.; Li, L.; Laursen, M.G.; et al. Solvent Control of Charge Transfer Excited State Relaxation Pathways in $\left[\mathrm{Fe}\left(2,2^{\prime} \text {-Bipyridine }\right)(\mathrm{CN})_{4}\right]^{2-}$. Phys. Chem. Chem. Phys. 2018, 20, 4238-4249. [CrossRef] [PubMed]

34. Liu, L.; Duchanois, T.; Etienne, T.; Monari, A.; Beley, M.; Assfeld, X.; Haacke, S.; Gros, P.C. A New Record Excited State ${ }^{3}$ MLCT Lifetime for Metalorganic Iron(II) Complexes. Phys. Chem. Chem. Phys. 2016, 18, 12550-12556. [CrossRef] [PubMed]

35. Pastore, M.; Duchanois, T.; Liu, L.; Monari, A.; Assfeld, X.; Haacke, S.; Gros, P.C. Interfacial Charge Separation and Photovoltaic Efficiency in Fe(II)-Carbene Sensitized Solar Cells. Phys. Chem. Chem. Phys. 2016, 18, 28069-28081. [CrossRef] [PubMed]

36. Hahn, A.W.; Van Kuiken, B.E.; al Samarai, M.; Atanasov, M.; Weyhermüller, T.; Cui, Y.-T.; Miyawaki, J.; Harada, Y.; Nicolaou, A.; DeBeer, S. Measurement of the Ligand Field Spectra of Ferrous and Ferric Iron Chlorides Using 2p3d RIXS. Inorg. Chem. 2017, 56, 8203-8211. [CrossRef] [PubMed]

37. Zimmer, P.; Burkhardt, L.; Friedrich, A.; Steube, J.; Neuba, A.; Schepper, R.; Müller, P.; Flörke, U.; Huber, M.; Lochbrunner, S.; et al. The Connection between NHC Ligand Count and Photophysical Properties in Fe(II) Photosensitizers: An Experimental Study. Inorg. Chem. 2018, 57, 360-373. [CrossRef] [PubMed] 
38. Duchanois, T.; Etienne, T.; Beley, M.; Assfeld, X.; Perpète, E.A.; Monari, A.; Gros, P.C. Heteroleptic Pyridyl-Carbene Iron Complexes with Tuneable Electronic Properties: Tuneable Pyridyl-Carbene Iron Complexes. Eur. J. Inorg. Chem. 2014, 2014, 3747-3753. [CrossRef]

39. Benkö, G.; Kallioinen, J.; Korppi-Tommola, J.E.I.; Yartsev, A.P.; Sundström, V. Photoinduced Ultrafast Dye-to-Semiconductor Electron Injection from Nonthermalized and Thermalized Donor States. J. Am. Chem. Soc. 2002, 124, 489-493. [CrossRef] [PubMed]

40. Pastore, M.; De Angelis, F. First-Principles Modeling of a Dye-Sensitized $\mathrm{TiO}_{2} / \mathrm{IrO}_{2}$ Photoanode for Water Oxidation. J. Am. Chem. Soc. 2015, 137, 5798-5809. [CrossRef] [PubMed]

41. Piccinin, S.; Rocca, D.; Pastore, M. Role of Solvent in the Energy Level Alignment of Dye-Sensitized NiO Interfaces. J. Phys. Chem. C 2017, 121, 22286-22294. [CrossRef]

42. Fredin, L.A.; Wärnmark, K.; Sundström, V.; Persson, P. Molecular and Interfacial Calculations of Iron(II) Light Harvesters. ChemSusChem 2016, 9, 667-675. [CrossRef]

43. Liu, L. Propriétés Photo-Physiques de Nouveaux Matériaux Moléculaires Pour La Conversion de Photons En Énergie. Ph.D. Thesis, Université de Strasbourg, Strasbourg, France, 2017.

(C) 2018 by the authors. Licensee MDPI, Basel, Switzerland. This article is an open access article distributed under the terms and conditions of the Creative Commons Attribution (CC BY) license (http://creativecommons.org/licenses/by/4.0/). 